Florida International University

FIU Digital Commons

\title{
Predictors of Adherence, Withdrawal Symptoms and Changes in Body Mass Index: Finding from the First Randomized Smoking Cessation Trial in a Low-income Country Setting
}

Ziyad Ben Taleb

zbent002@fiu.edu

DOI: 10.25148 /etd.FIDC000707

Follow this and additional works at: https://digitalcommons.fiu.edu/etd

Part of the Clinical Epidemiology Commons, and the Epidemiology Commons

\section{Recommended Citation}

Ben Taleb, Ziyad, "Predictors of Adherence, Withdrawal Symptoms and Changes in Body Mass Index: Finding from the First Randomized Smoking Cessation Trial in a Low-income Country Setting" (2016). FIU Electronic Theses and Dissertations. 2628.

https://digitalcommons.fiu.edu/etd/2628 


\title{
FLORIDA INTERNATIONAL UNIVERSITY
}

Miami, Florida

\section{PREDICTORS OF ADHERENCE, WITHDRAWAL SYMPTOMS AND CHANGES IN BODY MASS INDEX: FINDING FROM THE FIRST RANDOMIZED SMOKING CESSATION \\ TRIAL IN A LOW-INCOME COUNTRY SETTING}

\author{
A dissertation submitted in partial fulfillment of the \\ requirements for the degree of \\ DOCTOR OF PHILOSOPHY
}

in

PUBLIC HEALTH

by

Ziyad Ben Taleb

2016 
To: Dean Tomás R. Guilarte

Robert Stempel College of Public Health and Social Work

This dissertation, written by Ziyad Ben Taleb, and entitled Predictors of Adherence, Withdrawal Symptoms and Changes in Body Mass Index: Finding from the First Randomized Smoking Cessation Trial in a Low-income Country Setting, having been approved in respect to style and intellectual content, is referred to you for judgment.

We have read this dissertation and recommend that it be approved.

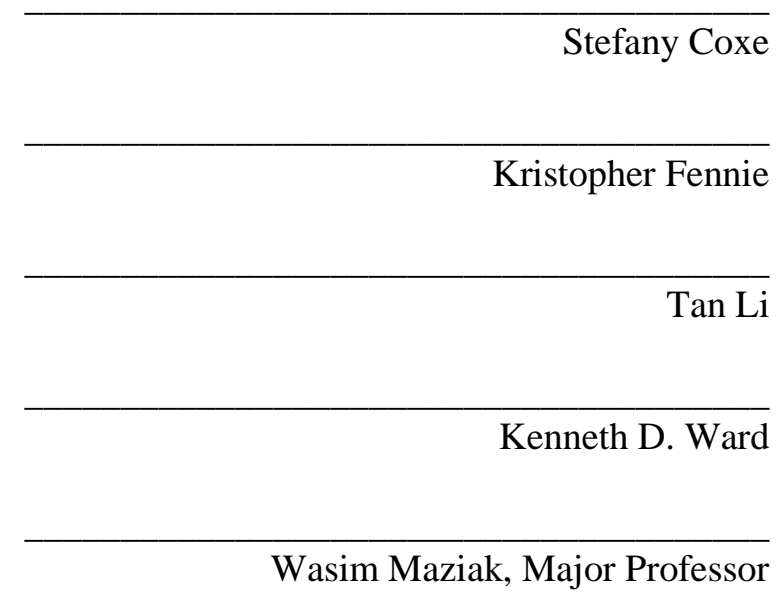

Date of Defense: June 28, 2016

The dissertation of Ziyad Ben Taleb is approved.

Dean Tomás R. Guilarte Robert Stempel College of Public Health and Social Work

Andrés G. Gil

Vice President for Research and Economic Development and Dean of the University Graduate School

Florida International University, 2016 
(C) Copyright 2016 by Ziyad Ben Taleb

All rights reserved 


\section{DEDICATION}

This dissertation is dedicated to my Mom and Dad and three brothers. Without their sacrifice, unconditional support and desire to provide me with the opportunity of a quality education, this work would not have been possible. 


\section{ACKNOWLEDGMENTS}

First of all, I want to thank Allah almighty for giving me the strength to successfully complete this work, despite all difficulties that I faced during the course of my study. I want to thank my parents for their continuous support throughout my long academic trip. My grateful appreciation to my major professor Dr.Wasim Maziak for his unlimited patience and support. His attitude in mentoring and guiding research creates a challenging and competitive atmosphere that stimulate critical thinking and creativity. I would also like to thank my committee members for always offering their time and expertise which helped me in finishing this work. A special thanks to Dr.Kenneth D. Ward for his continues feedback and insightful input that significantly improved the quality of my work. This work was supported by the National Institute on Drug Abuse (NIDA), (grants R01 DA024876). 
ABSTRACT OF THE DISSERTATION

PREDICTORS OF ADHERENCE, WITHDRAWAL SYMPTOMS AND CHANGES IN BODY

MASS INDEX: FINDING FROM THE FIRST RANDOMIZED SMOKING CESSATION

TRIAL IN A LOW-INCOME COUNTRY SETTING

\author{
by \\ Ziyad Ben Taleb \\ Florida International University, 2016 \\ Miami, Florida \\ Professor Wasim Maziak, Major Professor
}

The most commonly attributed causes of failure of smoking cessation are non-adherence to treatment, experiencing severe nicotine withdrawal symptoms and post-cessation weight gain. However, there is a lack of information regarding these factors among smokers who attempt to quit in low-income country settings. The main objective of this study was to identify predictors of: 1) adherence to cessation treatment; 2) severity of withdrawal symptoms: and 3) post-cessation changes in body mass index among 269 smokers who attempted to quit in a randomized smoking cessation trial in a low-income country setting (Aleppo, Syria). All participants received behavioral counseling and were randomized to receive either 6 weeks of nicotine or placebo patch and were followed for one year.

Findings from logistic regression showed that lower adherence to cessation treatment was associated with higher daily smoking, greater withdrawal symptoms, waterpipe use, being on placebo patch and the perception of receiving placebo patch. Generalized estimating equation (GEE) analyses indicated that throughout the study, lower total withdrawal score was associated with greater education, older age of smoking initiation, higher confidence in ability to quit, higher adherence to patch, lower nicotine dependence, lower reported depression, waterpipe use and the perception of receiving nicotine patches rather than placebo. Further, smoking abstainers gained 
1.8 BMI units (approximately $4.8 \mathrm{~kg}$ ) greater than non-abstainers over one year post quitting. In addition, greater BMI was associated with being female, smoking to control weight and having previously failed to quit due to weight gain.

In conclusion, nicotine dependence, waterpipe use and expectancies regarding cessation treatment are important factors that influence adherence to cessation treatment and severity of nicotine withdrawal symptoms. Moreover, targeted interventions that take into consideration the prevailing local and cultural influences on diet and levels of physical activity are recommended especially for females and smokers with weight concerns prior to quitting. Collectively, these findings will help in conducting future tailored effective cessation programs in Syria and other lowincome countries with similar levels of developments and tobacco use patterns. 


\section{TABLE OF CONTENTS}

CHAPTER

PAGE

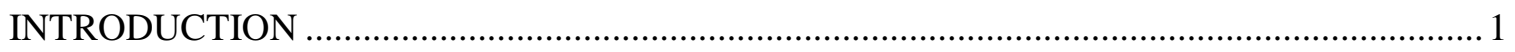

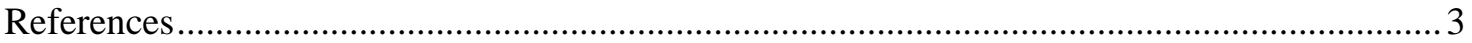

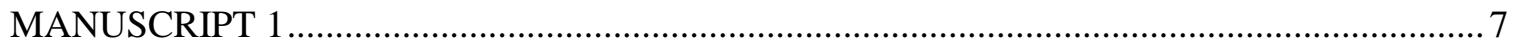

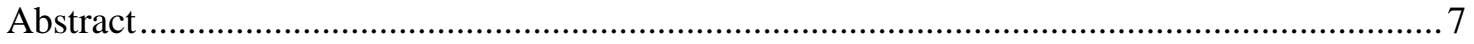

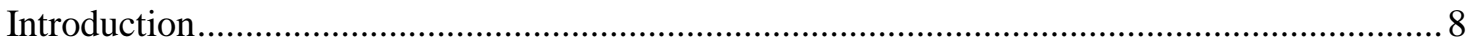

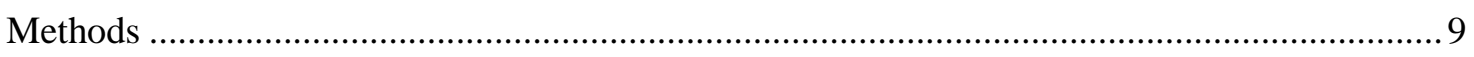

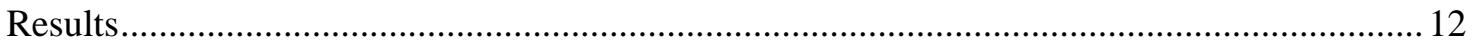

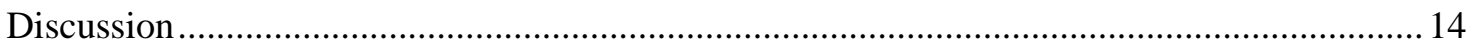

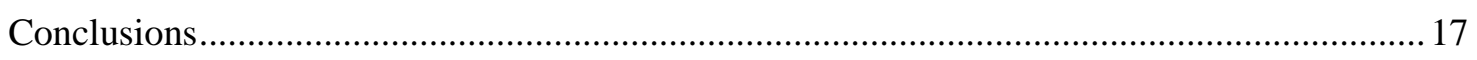

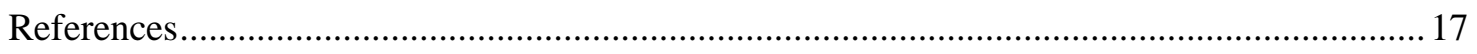

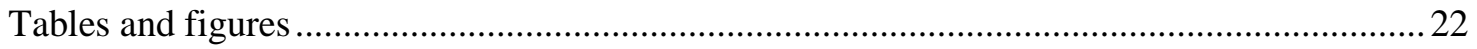

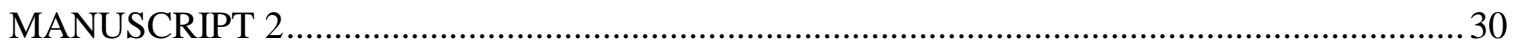

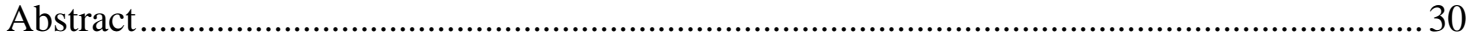

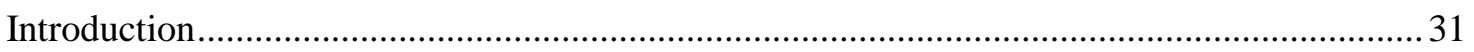

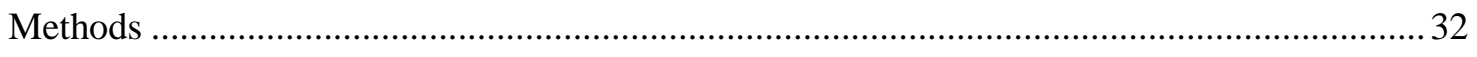

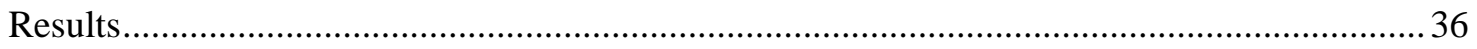

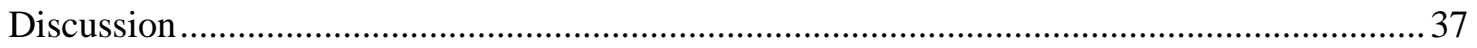

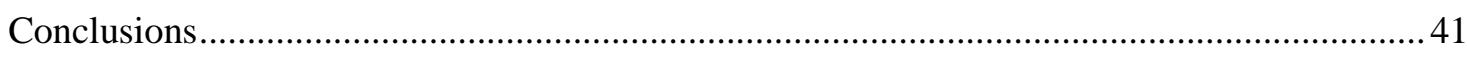

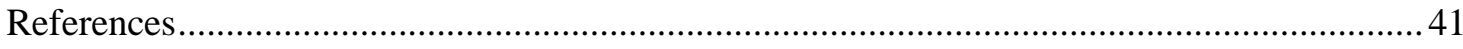

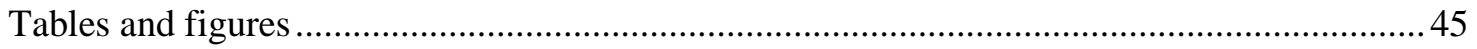

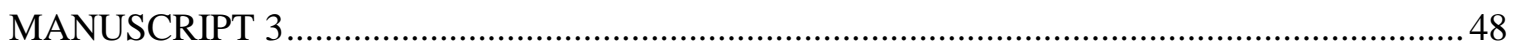

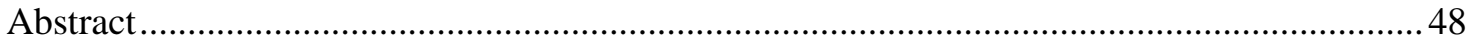

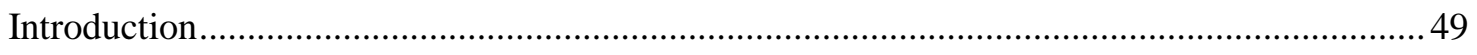

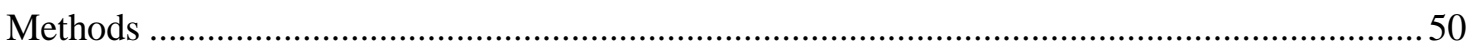

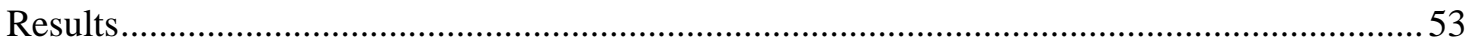

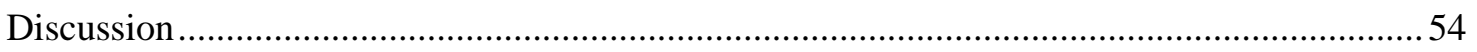




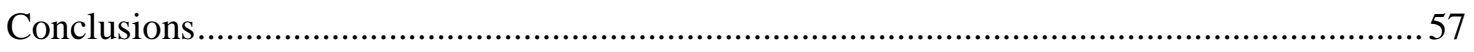

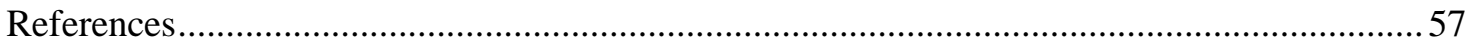

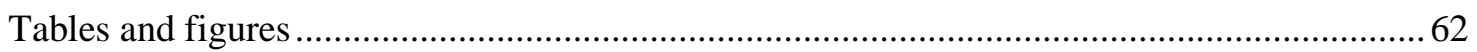

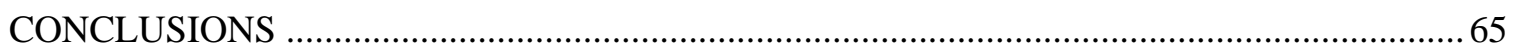

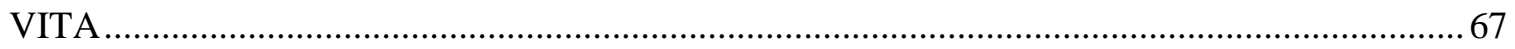




\section{ABBREVIATIONS AND ACRONYMS}

$\begin{array}{ll}\text { WHO } & \text { World Health Organization } \\ \text { FCTC } & \text { Framework Convention on Tobacco Control } \\ \text { FTND } & \text { Transdermal Nicotine } \\ \text { CES-D } & \text { Center for Epidemiologic Studies Depression Scale } \\ \text { OR } & \text { Odds ratios } \\ \text { MSPSS } & \text { Multidimensional Scale of Perceived Social Support } \\ \text { MNWS } & \text { Minnesota Nicotine Withdrawal Scale } \\ \text { GEE } & \text { Generalized estimating equation } \\ \text { RCT } & \text { Randomized controlled trial } \\ \text { BMI } & \text { Body mass index } \\ \text { NRT } & \text { Nicotine replacement therapy }\end{array}$




\section{INTRODUCTION}

Smoking tobacco kills approximately a third to half of its users, with an estimated 5 million annual global deaths, and if current trends continues, the death toll is expected to reach one billion by the end of this century (Shafey O, 2009; WHO, 2008; Adcock IM, 2011; Koczulla AR, 2010). On average, smokers die 10 to 15 years earlier than non-smokers (USDHHS, 2004).

Low-income countries are currently struggling with an epidemic of tobacco dependence and its complications. By the year 2030, it is predicted that more than $80 \%$ of tobacco deaths will be in developing countries (WHO, 2008). Most of low-income countries are still in the primary stages of the tobacco epidemic; therefore, in the future, this region of the world will most likely continue to experience increased smoking prevalence and growing number of tobacco caused diseases and deaths (Maziak et al, 2013; Ward et al, 2006).

Tobacco control, and in particular cessation programs, should be a priority for policy makers in low-income countries to achieve a considerable impact in the near future on the morbidity and mortality caused by smoking. However, in order for cessation strategies to be implemented comprehensively and according to best practices within tobacco control efforts, there is a need to overcome many regional challenges and cultural barriers. There is paucity of cessation programs in most low-income countries, and the few services that exist are modeled from western programs, which have different healthcare infrastructure settings and unique cultural characteristics (Maziak et al, 2004). However, despite the WHO's recommendation that tobacco dependence treatment should be a top public health priority (WHO, 2000), very little work has been done to promote and implement smoking cessation in low-income countries.

Smoking cessation is a continuous process that may involve a series of quit attempts before long term abstinence is accomplished. Despite that most smokers express a desire to quit, only around one third of them make attempts to quit and few are successful (Rigotti, 2002; USDHHS, 1990). Furthermore, approximately $80 \%$ of quitters relapse before reaching 6 months 
of abstinence (USDHHS, 1990). Many factors are associated with failure to quit smoking. Some of the most cited factors are experiencing nicotine withdrawal symptoms, non-adherence to cessation treatment and gaining weight post-cessation.

The relationship between adherence to treatment and successful quit attempts is well recognized (Raupach et al, 2014). Therefore, a great deal of attention has been directed toward maintaining patient adherence to treatment (e.g., attendance at counseling sessions, taking medication as instructed) in smoking cessation interventions (Shiffman et al., 2008; Alterman, 1999). As such, factors contributing to better adherence to treatment have been investigated in the past to guide the development of cessation interventions and to improve cessation rates in highincome countries (Alterman et al., 1999; Berg et al., 2013; Cooper et al., 2004; Patterson et al., 2003). Nevertheless, no studies have looked at patterns and correlates of adherence to cessation treatment in a low-income country setting.

In addition, experiencing nicotine withdrawal symptoms is one of the biggest challenges that faces smokers while quitting. When smokers are deprived of nicotine, they develop withdrawal symptoms and pronounced cognitive and attentional deficiencies that are relieved when consuming nicotine (Evans and Drobes, 2009). Prior research highlighted some of the important factors influencing nicotine withdrawal symptoms. These include number of cigarettes smoked per day, motivation to smoke, and depression (Morrell et al 2008; West and Russell 1985). Despite the extensive literature on evaluating nicotine withdrawal symptoms in populations from high-income countries (Bidwell et al. 2013; Gritz et al. 1991; Hendricks and Leventhal 2013; Hendricks et al. 2014; Neiro et al. 2014; Piasecki et al. 2003; West et al.2008), such information in low-income countries lags behind.

Finally, post-cessation weight gain is commonly cited as a major cause of failure to quit smoking (Jeffery et al., 2000; Perkins, 1993). It is a well-established, that quitters gain weight 
after stopping smoking (Flegal et al., 1995). In general, quitters gain an average of 4 to $5 \mathrm{~kg}$ after one year (Aubin et al., 2012). One of the most important consequences of weight gain post smoking cessation is relapsing back to smoking (Klesges et al., 1997). Evidence from high-income countries has documented several factors associated with post-cessation weight gain such as higher nicotine dependence and lower socioeconomic status (Wane et al., 2010; Williamson et al 1991; Swan and Carmelli, 1995). However, prevalence and predictors of post-cessation weight gain may be different in low income compared to high income countries, since many risk factors differ. For example, people living in low-income countries may be less concerned about weight gain and have different rates of obesity than those living in high-income countries probably due to differences in socioeconomic status, and cultural and life style factors such as level of physical activity and diet choices (Badran and Laher, 2011; Fouad et al., 2006).

In Summary, lack of information regarding factors that influence adherence to cessation treatment, severity of nicotine withdrawal symptoms and weight gain among smokers who attempt to quit in low-income country settings warrant further research. The aim of this dissertation is to identify predictors of adherence to cessation treatment, nicotine withdrawal symptoms and changes in body mass index (BMI) among smokers who participated in a randomized cessation trial in a primary health care setting in Aleppo, Syria.

\section{References}

Adcock, I. M., Caramori, G., \& Barnes, P. J. (2011). Chronic obstructive pulmonary disease and lung cancer: new molecular insights. Respiration, 81(4), 265-284.

Alterman, A. I., Gariti, P., Cook, T. G., Cnaan, A. (1999). Nicodermal patch adherence and its correlates. Drug Alcohol Depend. 53, 159-165.

Aubin, H. J., Farley, A., Lycett, D., Lahmek, P., \& Aveyard, P. (2012). Weight gain insmokers after quitting cigarettes: meta-analysis. BMJ: British Medical Journal, 345.

Badran, M., \& Laher, I. (2011). Obesity in Arabic-speaking countries. Journal of Obesity, 2011 
Berg, C. J., Ahluwalia, J. S., Cropsey, K. (2013). Predictors of adherence to behavioral counseling and medication among female prisoners enrolled in a smoking cessation trial. J. Correct. Health Care 19, 236-247.

Bidwell, L.C., Leventhal A.M., Tidey, J.W., Brazil, L., Niaura, R.S., Colby, S.M. (2013) Effects of abstinence in adolescent tobacco smokers: Withdrawal symptoms, urge, affect, and cue reactivity. Nicotine Tob Res 15:457-464. doi: 10.1093/ntr/nts 155 .

Cooper, T. V., DeBon, M. W., Stockton, M., Klesges, R. C., Steenbergh, T. A., SherrillMittleman, D., Jennings, L.C., Johnson, K. C. (2004). Correlates of adherence with transdermal nicotine. Addict. Behav. 29, 1565-1578.

Evans, D. E., \& Drobes, D. J. (2009). Nicotine self-medication of cognitive-attentional processing. Addiction biology, 14(1), 32-42.

Flegal, K. M., Troiano, R. P., Pamuk, E. R., Kuczmarski, R. J., \& Campbell, S. M. (1995). The influence of smoking cessation on the prevalence of overweight in the United States. New England Journal of Medicine, 333(18), 1165-1170.

Fouad, M. F., Rastam, S., Ward, K. D., \& Maziak, W. (2006). Prevalence of obesity and its associated factors in Aleppo, Syria. Prevention and Control,2(2), 85-94.

Gritz, E.R., Carr, C.R., Marcus, A.C. (1991). The tobacco withdrawal syndrome in unaided quitters. Br J Addict 86: 57-69. doi: 10.1111/j.1360-0443.1991.tb02629.x

Hendricks, P.S., Leventhal, A.M. (2013). Abstinence-related expectancies predict smoking withdrawal effects: implications for possible causal mechanisms. Psychopharmacology 230: 363-373. doi: 10.1007/s00213-013-3169-7.

Jeffery, R. W., Hennrikus, D. J., Lando, H. A., Murray, D. M., \& Liu, J. W. (2000). Reconciling conflicting findings regarding postcessation weight concerns and success in smoking cessation. Health Psychology, 19(3), 242.

Klesges, R. C., Winders, S. E., Meyers, A. W., Eck, L. H., Ward, K. D., Hultquist, C. M., ... \& Shadish, W. R. (1997). How much weight gain occurs following smoking cessation: A comparison of weight gain using both continuous and point prevalence abstinence. Journal of consulting and clinical psychology, 65(2), 286.

Koczulla, A.R., Noeske, S., Herr, C., Jörres, R.A., Römmelt, H., Vogelmeier, C., Bals, R. (2010). Acute and chronic effects of smoking on inflammation markers in exhaled breath condensate in current smokers. Respiration,79:61-67.

Maziak, W., Eissenberg, T., Klesges, R. C., Keil, U., \& Ward, K. D. (2004). Adapting smoking cessation interventions for developing countries: a model for the Middle East. The International Journal of Tuberculosis and Lung Disease, 8(4), 403-413. 
Maziak, W., Nakkash, R., Bahelah, R., Husseini, A., Fanous, N., \& Eissenberg, T. (2013). Tobacco in the Arab world: old and new epidemics amidst policy paralysis. Health policy and planning, czt055.

Morrell, H.E., Cohen, L.M., Al'Absi, M. (2008). Physiological and psychological symptoms and predictors in early nicotine withdrawal. Pharmacol Biochem Behav, 89: 272-278. doi: 10.1016/j.pbb.2007.12.020.

Neiro, B.P., Durán, A.L., Del Río, E.F., Pradeda ÚM, Brandon TH, Iglesias EB. (2014). Craving and nicotine withdrawal in a Spanish smoking cessation sample. Adicciones, 26:230-237.

Patterson, F., Jepson, C., Kaufmann, V., Rukstalis, M., Audrain-McGovern, J., Kucharski, S., Lerman, C.(2003). Predictors of attendance in a randomized clinical trial of nicotine replacement therapy with behavioral counseling. Drug alcohol depend. 72, 123-131.

Perkins, K. A., Marcus, M. D., Levine, M. D., D'Amico, D., Miller, A., Broge, M., ... \& Shiffman, S. (2001). Cognitive-behavioral therapy to reduce weight concerns improves smoking cessation outcome in weight-concerned women.Journal of consulting and clinical psychology, 69(4), 604.

Piasecki, T.M., Jorenby, D.E., Smith, S.S., Fiore, M.C., Baker, T.B. (2003). Smoking withdrawal dynamics: II. Improved tests of withdrawal-relapse relations. J Abnorm Psychol,112: 14.doi: 10.1037/0021-843X.112.1.14.

Raupach, T., Brown, J., Herbec, A., Brose, L., \& West, R. (2014). A systematic review of studies assessing the association between adherence to smoking cessation medication and treatment success. Addiction, 109(1), 35-43.

Rigotti, N. A. (2002). Treatment of tobacco use and dependence. New England Journal of Medicine, 346(7), 506-512.

Shafey O, Eriksen M, Ross H, Mackay J. (2009). The Tobacco Atlas, ed 3. Georgia, American Cancer Society.

Shiffman, S., Sweeney, C. T., Ferguson, S. G., Sembower, M. A., Gitchell, J. G. (2008). Relationship between adherence to daily nicotine patch use and treatment efficacy: secondary analysis of a 10 week randomized, double-blind, placebo-controlled clinical trial simulating over-the-counter use in adult smokers. Clin. Ther, 30, 1852-1858.

Swan, G. E., \& Carmelli, D. (1995). Characteristics associated with excessive weight gain after smoking cessation in men. American Journal of Public Health, 85(1), 73-77.

US Department of Health and Human Services. (1990). The health benefits of smoking cessation: A report of the Surgeon General. Atlanta, GA: US Department of Health and Human Services, Centers for Disease Control and Prevention, National Center for Chronic Disease Prevention and Health Promotion, Office on Smoking and Health. 
US Department of Health and Human Services. (2004). the health consequences of smoking: a report of the Surgeon General. Atlanta, GA: US Department of Health and Human Services, Centers for Disease Control and Prevention, National Center for Chronic Disease Prevention and Health Promotion, Office on Smoking and Health, 62.

Wane, S., Van Uffelen, J. G., \& Brown, W. (2010). Determinants of weight gain in young women: A review of the literature. Journal of Women's Health,19(7), 1327-1340.

Ward, K. D., Eissenberg, T., Rastam, S., Asfar, T., Mzayek, F., Fouad, M. F., ... \& Maziak, W. (2006). The tobacco epidemic in Syria. Tobacco control, 15(suppl 1), i24-i29.

West, R., Baker, C. L., Cappelleri, J.C., Bushmakin, A.G. (2008). Effect of varenicline and bupropion SR on craving, nicotine withdrawal symptoms, and rewarding effects of smoking during a quit attempt. Psychopharmacology 197(3): 371-377. doi:

10.1007/s00213-007-1041-3

West, R.J, Russell, M.A. (1985) Pre-abstinence smoke intake and smoking motivation as predictors of severity of cigarette withdrawal symptoms. Psychopharmacology, 87: 334336. doi: 10.1007/BF00432717

Williamson, D. F., Madans, J., Anda, R. F., Kleinman, J. C., Giovino, G. A., \& Byers, T. (1991). Smoking cessation and severity of weight gain in a national cohort. New England Journal of Medicine, 324(11), 739-745.

World Health Organization Europe. (2000). Partnership to reduce tobacco dependence. Copenhagen: World Health Organization.

World Health Organization: Report on the Global Tobacco Epidemic. (2008). The MPOWER Package. Geneva, WHO. http://whqlibdoc.who.int/publications/2008/

9789241596282_eng.pdf (accessed December 12, 2011). 


\title{
MANUSCRIPT 1
}

(C) Copyright 2016

Ben Taleb, Z, Ward, K. D., Asfar, T., Bahelah, R., \& Maziak, W. (2015). Predictors of adherence to pharmacological and behavioral treatment in a cessation trial among smokers in Aleppo, Syria. Drug and Alcohol Dependence, 153, 167-172

\begin{abstract}
Background: The development of evidence-based smoking cessation programs is in its infancy in developing countries, which continue to bear the main brunt of the tobacco epidemic. Adherence to treatment recommendations is an important determinant of the success of smoking cessation programs, but little is known about factors influencing adherence to either pharmacological or behavioral treatment in developing countries settings. Aim: To examine the predictors of adherence to cessation treatment in a low-income developing country. Methods: Predictors of adherence to pharmacological and behavioral treatment were identified by analyzing data from a multi-site, twogroup, parallel-arm, double-blind, randomized, placebo-controlled smoking cessation trial in primary care clinics in Aleppo, Syria. Participants received 3 in-person behavioral counseling sessions plus 5 brief follow-up phone counseling sessions, and were randomized to either 6 weeks of nicotine or placebo patch. Results: Of the 269 participants, $68 \%$ adhered to pharmacological treatment, while $70 \%$ adhered to behavioral counseling. In logistic regression modeling, lower adherence to pharmacological and behavioral treatment was associated with higher daily smoking at baseline, greater withdrawal symptoms, and perception of receiving placebo instead of active nicotine patch. Women showed lower adherence than men to behavioral treatment, while being assigned to placebo condition and baseline waterpipe use were associated with lower adherence to pharmacological treatment. Conclusion: Adherence to cessation treatment for cigarette smokers in low-income countries such as Syria may benefit from integrated cessation components that provide
\end{abstract}


intensive treatment for subjects with higher nicotine dependence, and address concurrent waterpipe use at all stages.

KEYWORDS: adherence; cessation; cigarettes; developing countries; smoking

\section{Introduction}

Tobacco smoking remains the leading cause of preventable deaths world-wide. Currently, tobacco is responsible for an estimated 6 million deaths every year (Erikson et al, 2013). This annual death toll is expected to increase to 10 million within the next $20-30$ years, with $80 \%$ of these deaths occurring in developing countries (WHO, 2013a). These trends call for comprehensive approaches for tobacco control, especially in low-income countries, which continue to bear most of the brunt of the tobacco epidemic (World Bank, 2010).

Promoting smoking cessation, is a cornerstone in the fight to reduce tobacco related morbidity and mortality (WHO, 2013a). This is why, one of the main articles (14) of the Framework Convention on Tobacco Control (FCTC) requires governments to take effective measures to promote cessation of tobacco use and adequate treatment for tobacco dependence (WHO, 2010). At least in developed countries, the application of a mixture of behavioral and pharmacological cessation interventions has been shown to help a proportion of smokers to quit smoking (Fiore et al., 2008). Unfortunately, in developing countries, where most of the world smokers reside (Jha et al., 2006), infrastructure for smoking cessation is lacking and little work is being done to develop effective cessation interventions that take into account local smoking patterns, health care resources and culture. (Maziak et al., 2004). For example, in Syria, a Middle Eastern country with high prevalence of cigarettes and waterpipe smoking (WHO, 2013b;Ward et al., 2006) there are no clinical practice standards, specialty cessation clinics or pharmacological agents available to assist smokers to quit (Asfar et al., 2008, 2011; Maziak et al., 2004; Ward et al, 2013). 
To date there is only one randomized clinical trial of a behavioral/pharmacological smoking cessation intervention that was conducted in a developing country setting (Ward et al., 2013). Results from this trial showed that combined pharmacological and behavioral treatment induced cessation in $12 \%$ of participants at one year post-treatment. This study along with a bulk of evidence from developed countries highlighted the importance of adherence to treatment (e.g., attendance at counseling sessions, taking medication as instructed) in predicting successful cessation outcomes (Shiffman et al., 2008; Alterman, 1999). As such, factors contributing to better adherence to cessation treatment have received substantial attention in order to guide the development of approaches that improve adherence to cessation interventions (Alterman et al., 1999; Berg et al., 2013; Cooper et al., 2004; Patterson et al., 2003). However, little if any evidence currently exists to assist in fostering adherence to cessation treatments in developing countries. The current study aims to address this knowledge gap by identifying potential predictors of adherence to pharmacological and behavioral treatment in a developing country's health care setting (Syria).

\section{Methods}

\section{Study design}

This study utilized data from a multi-site two-group, parallel-arm, double-blind, randomized, placebo-controlled trial conducted in primary care clinics in Aleppo, Syria from 2007 to 2008. Full details of the trial and methods are published elsewhere (Ward et al., 2013). Eligible and interested smokers were randomized to receive either behavioral cessation counseling + active transdermal nicotine patches $(\mathrm{TN})$ or behavioral cessation counseling + placebo TN. A total of 269 smokers were recruited, 18-65 years old, who had smoked $>5$ cigarettes/day for at least one year. Participants were patients who resided within the catchment area of one of the four primary health care clinics included in the study. Each clinic had a primary care physician who served as a 
cessation coordinator, liaised between other physicians and clinic-staff to ensure adherence to the study protocol, and delivered the intervention to participants.

\section{Pharmacologic Intervention}

Patients in the active treatment group received a six-week supply of Nicotinell ${ }^{\mathrm{TM}}$ patches, 24-hour dose, using a step-down algorithm. Patients in the placebo group received the same stepdown algorithm. Placebo patches were provided by a local manufacturer.

\section{Behavioral counselling}

All patients received behavioral cessation counseling using approaches shown to be effective in developed countries (Abrams and Niaura, 2003; Fiore et al., 2008) and adapted for the local culture based on previous research (Asfar et al., 2008). Three individual, in-person sessions (approximately 30 minutes each) and 5 brief (approximately 10-minute) phone calls, were delivered by the cessation coordinator. Participants provided baseline demographic data, smoking related information (e.g., smoking history, level of dependence, previous quit attempts, readiness to quit smoking), and completed additional questionnaires to assess quitting self-efficacy, stage of change, withdrawal symptoms, perceived social support, and depression/mood. Participants then were assigned to one of two treatment conditions [Arm A ( $n=134)$ : behavioral counseling + active TN vs. Arm B ( $n=135)$ : behavioral counseling + placebo TN] using random permuted blocks, stratified by clinic and gender.

\section{$\underline{\text { Measures }}$}

\section{Baseline predictors}

Socio-demographic variables included age, gender, marital status, number of people in the house, years of education and religion. Smoking-related variables included number of years as a cigarette smoker; current amount smoked (cigarettes/day); previous successful quit attempts 
defined as quitting smoking for at least 24 hours in the past six months; the Readiness To Quit Ladder (Biener and Abrams, 1991); a single item, Likert-type scale assessing confidence in one's ability to quit; the three subscales of the Smoking Self-Efficacy/Temptations Questionnaire (Long Form)-Positive Affect/Social Situations, Negative Affect Situations, and Habitual/Craving Situations (Velicer et al. ,1990); the Fagerström Test for Nicotine Dependence (FTND) (Heatherton et al. ,1991); waterpipe use status and tobacco withdrawal symptomatology using the Minnesota Nicotine Withdrawal Scale (MNWS) (Hughes and Hatsukami, 1986). We calculated the mean of eight scale items to obtain a total withdrawal score. Other variables included: perceived social support (Zimet et al., 1988; Zimet et al., 1990), and depressive symptomatology using the Center for Epidemiologic Studies Depression Scale (CES-D) (Radloff, 1977; Thomas et al., 2001). To assess blindness during treatment, patients indicated whether they believed they had received nicotine or placebo patch.

\section{Adherence to patch}

Participants were queried weekly for the duration of the treatment (six weeks) on whether they had followed treatment instructions to use one patch every day over the past week. Based on the literature (Kopjar et al., 2003; Nachega et al., 2006; Ruddy and Partridge, 2009, Berg et al., 2013), we defined being adherent to patch use as responding "yes" to this question during at least 5 of the 6 weeks (>80\%). Accordingly, adherence to patch was set up as a dichotomous variable (non-adherent $=0$, adherent $=1$ ).

\section{Adherence to behavioral counselling}

Following previous work (Asfar et al., 2008; Klesges et al., 1988; Mizes et al., 1998; Patterson et al., 2003), adherence to behavioral counselling was set as a dichotomous variable (nonadherent $=0$, adherent $=1$ ) indicating whether the subjects completed all vs. some sessions. 
Specifically, the variable distinguished participants who completed all three in-person sessions + five phone calls from those who missed at least one session or a phone call.

\section{$\underline{\text { Statistical Analysis }}$}

Baseline characteristics (socio-demographic, smoking and psychosocial characteristics) were compared according to adherence to pharmacological and behavioral treatment for all subjects using the chi-square test for categorized variables and t-tests or Mann-Whitney $U$ tests where appropriate for continuous variables. Bivariate correlations for all predictor variables revealed no multicollinearity. This was also inspected by checking for extraordinary estimated coefficients and standard errors, which would have suggested the existence of collinearity. The outcomes of interest were adherence to patch use and adherence to behavioral counseling. Separate logistic regression models were developed for each outcome variable. All predictors (socio-demographic, smokingrelated, and psychosocial variables) significant at the $<0.20$ level in bivariate analyses were entered into the models using backward stepwise entry, with only those variables contributing at the $<0.05$ level being allowed to remain in the model. The Wald statistic was used to assess the contribution of each predictor to the overall model. Adjusted odd ratios and $95 \%$ Confidence intervals were calculated and reported. All analyses controlled for age and sex. Data were analyzed using SPSS version 21 (SPSS Inc., Chicago, IL, USA).

\section{Results}

\section{Characteristics of the sample}

Males comprised $78 \%$ of the sample. The mean age was 39.9 years $(\mathrm{SD}=11.4)$, with a mean of 10.2 years of education $(\mathrm{SD}=4.0)$. The mean number of cigarettes smoked per day was $27.7(\mathrm{SD}=12.7)$, while the mean age for the onset of daily smoking was 18.6 years $(\mathrm{SD}=5.3)$ and the mean Fagerström nicotine dependence score was $5.7(\mathrm{SD}=2.2)$. The two treatment groups 
(nicotine vs. placebo) did not differ significantly on any of these variables at baseline. Out of the 269 study participants, $183(68 \%)$ were adherent to patch use and $187(70 \%)$ were adherent to behavioral counselling sessions. To assess blindness during treatment, patients indicated whether they believed they had received nicotine or placebo patch, in which $62 \%$ of participants on nicotine patch guessed their assignment correctly as compared to only $40 \%$ of participants on placebo patch $(\mathrm{P}<0.001)$.

$\underline{\text { Bivariate associations }}$

Table1 summarizes the bivariate analysis for baseline characteristics by adherence to patch and behavioral counseling.

\section{Adherence to patch use}

Lower adherence was associated with greater number of cigarettes smoked per day at baseline ( $\mathrm{P}=0.001)$, higher FTND score $(\mathrm{P}=.041)$, waterpipe smoking $(\mathrm{P}=.005)$, self-perception of being allocated to placebo group $(\mathrm{P}=<.001)$, greater total withdrawal symptoms $(\mathrm{P}=.036)$, being on placebo treatment $(\mathrm{P}=0.002)$, and lower readiness to quit score $(\mathrm{P}=.033)$.

\section{Adherence to behavioral counseling}

Lower adherence to behavioral treatment was associated with greater number of cigarettes smoked per day at baseline $(\mathrm{P}=.002)$, self-perception of being allocated to placebo group $(\mathrm{P}=$ $<.001)$, greater total withdrawal symptoms $(\mathrm{P}=.022)$ lower readiness to quite score $(\mathrm{P}=.027)$, and younger age $(\mathrm{P}=.024)$.

\section{$\underline{\text { Regression modelling }}$}

For the adjusted model predicting adherence to pharmacologic treatment (Table.2), participants who received nicotine patch $(\mathrm{OR}=2.5 ; 95 \% \mathrm{CI}=1.3-4.7)$, perceived themselves as 
being on nicotine patch $(\mathrm{OR}=4.3 ; 95 \% \mathrm{CI}=2.2-9.3)$, and who did not use waterpipe $(\mathrm{OR}=4.2 ; 95 \%$ $\mathrm{CI}=1.6-11.1$, were more likely to adhere to patch usage. Participants who smoked a greater number of cigarettes per day at baseline $(\mathrm{OR}=0.97 ; 95 \% \mathrm{CI}=0.94-0.99)$ and had higher withdrawal symptoms $(\mathrm{OR}=0.97 ; 95 \% \mathrm{CI}=0.95-0.98)$ were less likely to adhere to patch usage.

The adjusted model predicting adherence to behavioral counseling (Table.2) shows that male participants $(\mathrm{OR}=2.4 ; 95 \% \mathrm{CI}=1.2-4.9)$ and those who perceived themselves as being on nicotine patch $(\mathrm{OR}=4.6 ; 95 \% \mathrm{CI}=2.4-8.8)$ were more likely to adhere to counseling. On the other hand, participant who smoked a greater number of cigarettes per day at baseline $(\mathrm{OR}=0.97 ; 95 \%$ $\mathrm{CI}=0.94-0.98)$ and who had higher withdrawal score $(\mathrm{OR}=0.98 ; 95 \% \mathrm{CI}=0.96-0.99)$ were less likely to adhere to counseling.

For both study outcomes, we examined several interaction terms, including treatment group with baseline withdrawal score, number of cigarettes smoked per day, and perception of treatment allocation (i.e., belief that one had received nicotine and not placebo). We also examined the interaction between gender and baseline withdrawal score. All interaction terms yielded nonsignificant results (all p-values were > 0.27).

\section{Discussion}

This is the first study to examine predictors of adherence to smoking cessation treatment in a developing country's health care context. Our findings indicate that lower adherence to pharmacological and behavioral treatments was associated with heavier smoking rate at baseline, greater withdrawal symptomatology, and participants' belief they were receiving placebo instead of active nicotine patch. Women showed lower adherence than men to behavioral treatment, while being assigned to the placebo condition and baseline waterpipe use were associated with lower adherence to pharmacologic treatment. Our findings suggest that adherence to cessation treatment for cigarette smokers in low-income countries such as Syria may benefit from integrated cessation 
components that provide intensive treatment for subjects with higher nicotine dependence, and address concurrent waterpipe use at all stages. Such novel insights on factors that influence adherence to cessation treatment in a developing country's setting, can help improve cessation treatments for smokers living in countries at similar level of development.

Adherence rates to pharmacological and behavioral treatment achieved in this study appears comparable to studies that have been done in developed countries. For example, the adherence rate to pharmacological treatment in our study (68\%) was in agreement with a previous study that examined adherence to medication among adult smokers in two smoking cessation trials in the US (Hays et al., 2010). Moreover, adherence rate to behavioral counseling sessions of $70 \%$ achieved in our study also appears comparable with rates achieved in a cessation trial that evaluated adherence to seven sessions of behavioral counseling among adult smokers in the US. (Patterson et al., 2003). This shows that high adherence rates can be achieved in developing country settings when applying standardized procedures and protocols to follow-up with study's participants.

Overall, our study indicates the importance of nicotine dependence as a barrier to adherence to pharmacological and behavioral cessation treatments. Greater tobacco use at baseline and more severe tobacco withdrawal symptomatology both indicate greater dependence, and were associated with lower adherence in our study. A higher FTND score also was associated with lower adherence in bivariate level $(\mathrm{P}=.041)$, although such association was outside the significant level in the multivariable models. While nicotine dependence appears to make adherence difficult, it is encouraging that in the current study, the assignment to active nicotine, compared to placebo, was associated with a more than two folds greater odds of being adherent to pharmacologic treatment. This indicates that nicotine replacement therapy can enhance adherence to treatment in highly dependent smokers. 
One of the unique findings of this study that is likely to be relevant to most countries in the Middle East, is the association between lower adherence to pharmacological treatment and concurrent waterpipe use. Waterpipe is a common form of tobacco use in the Middle East that delivers substantial amounts of nicotine and is associated with nicotine dependence (Aboaziza and Eissenberg; Maziak, 2014). Furthermore, studies that looked into concurrent use of tobacco products has shown that dual smokers have the highest prevalence of nicotine dependence in contrast to exclusive users (Post et al., 2010; Timberlake, 2008; Tomar et al. 2010). While such evidence is indicative of a potential role of nicotine dependence in mediating the association between waterpipe smoking and lower adherence, this cannot be asserted based on this finding alone. This association however, suggests that cessation efforts in societies, where cigarettes are not the only main tobacco use method, should devote special attention to cultural-specific smoking behaviors (Maziak et al, 2004, Asfar et al, 2008). Previous studies from the same population, show that cigarette smokers can revert to waterpipe smoking during quit attempts, which can facilitate relapse (Hammal et al, 2008; Asfar et al, 2008). As a result, asking about waterpipe smoking and emphasizing cessation of all tobacco use can be instrumental to cessation success.

Interestingly, our data show that women were less adherent to behavioral counselling than men. This might be attributed to social barriers and gender roles (Maziak, 2006) that might prevent women from freeing themselves from their home duties in order to commit to behavioral counselling. Factors such as transportation, child care and other household responsibilities may have played a role in lowering women's adherence to behavioral counselling. On the other hand, adherence to pharmacologic treatment did not differ by gender, which understandably does not require attendance and can be done at home.

Beliefs and expectations about nicotine patch's effectiveness has been shown to affect adherence beyond whether an active nicotine or a placebo patch is received (Darredeau and Barrett, 
2010). In our study, adherence to pharmacologic and behavioral treatment was greater among those who believed that they had received nicotine compared with those who believed they had received placebo, regardless of the actual patch assignment. So believing that one may have received a nicotine patch even if it was in fact a placebo may have increased compliance or encouraged adherence to cessation treatment in general. This suggests that, psychological factors may play an important role in participants' subjective responses to treatment assignment, the effects of which cannot be solely attributed to the direct pharmacological effects of nicotine.

Our study comes with limitations. First, a relatively small sample size may not have allowed us to detect differences that were clinically meaningful but not statistically significant. Thus, we discussed marginally significant findings that might warrant future investigation. Secondly, adherence to patch use was based on self-report. Nevertheless, self-report of adherence to treatment has been widely used in the literature for both smoking cessation treatment and other medications in general (Alterman, et al., 1999; Cooper et al., 2004; Hollands et al., 2013; Okuyemi et al., 2010; Stein et al., 2006).

\section{Conclusions}

This study provides the first evidence about factors influencing adherence to cessation treatments in a low income country setting in the Middle East. It suggests that adherence to cessation treatment for cigarette smokers in low-income countries such as Syria may benefit from integrated cessation components that provide intensive treatment for subjects with higher nicotine dependence, and address concurrent waterpipe use at all stages.

\section{References}

Aboaziza, E., Eissenberg, T. (2014). Waterpipe tobacco smoking: what is the evidence that it supports nicotine/tobacco dependence?. Tob. Control, 24, 44-53 
Abrams, D. B., Niaura, R. (Eds.). (2003). The tobacco dependence treatment handbook: A guide to best practices. Guilford Press.

Alterman, A. I., Gariti, P., Cook, T. G., Cnaan, A. (1999). Nicodermal patch adherence and its correlates. Drug Alcohol Depend. 53, 159-165.

Asfar, T., Vander Weg, M. W., Maziak, W., Hammal, F., Eissenberg, T., Ward, K. D.(2008). Outcomes and adherence in Syria's first smoking cessation trial. Am. J. Health Behav. 32, 146-156.

Asfar, T., Al-Ali, R., Ward, K. D., Vander Weg, M. W., Maziak, W. (2011). Are primary health care providers prepared to implement an anti-smoking program in Syria? Patient Educ. Couns. 85, 201-205.

Berg, C. J., Ahluwalia, J. S., Cropsey, K. (2013). Predictors of adherence to behavioral counseling and medication among female prisoners enrolled in a smoking cessation trial. $J$. Correct. Health Care, 19, 236-247.

Biener, L., Abrams, D. B. (1991). The Contemplation Ladder: validation of a measure of readiness to consider smoking cessation. Health. Psychol, 10, 360-365.

Cooper, T. V., DeBon, M. W., Stockton, M., Klesges, R. C., Steenbergh, T. A., SherrillMittleman, D., Jennings, L.C., Johnson, K. C. (2004). Correlates of adherence with transdermal nicotine. Addict. Behav, 29, 1565-1578.

Darredeau, C., Barrett, S. P. (2010). The role of nicotine content information in smokers' subjective responses to nicotine and placebo inhalers. Hum. Psychopharmacol. 25, 577-581.

Erikson, M., Mackay, J., Ross, H. (2013). The tobacco atlas (No. Ed. 4). American Cancer Society.

Fiore, M. C., Jaen, C. R., Baker, T. B., Bailey, W. C., Bennett, G., Benowitz, N. L., Christiansen B.A., Connell, M., Curry, S. J., Dorfman, S. F. A. (2008). A clinical practice guideline for treating tobacco use and dependence: 2008 update. A US Public Health Service report. Am. J. Prev Med. 35, 158-76.

Hammal, F., Mock, J., Ward, K. D., Eissenberg, T.,Maziak, W. (2008). A pleasure among friends: how narghile (waterpipe) smoking differs from cigarette smoking in Syria. Tob. Control 17, e3-e3.

Hays, J. T., Leischow, S. J., Lawrence, D., Lee, T. C. (2010). Adherence to treatment for tobacco dependence: Association with smoking abstinence and predictors of adherence. Nicotine Tob. Res, 12, 574-581

Heatherto,n T. F., Kozlowski, L. T., Frecker, R. C., Fagerstrom, K. O., 1991. The fagerstrom test for nicotine dependence: a revision of the fagerstrom tolerance questionnaire. Br. J. Addict, 86, 1119-27. 
Hollands, G. J., Sutton, S., McDermott, M. S., Marteau, T. M., \& Aveyard, P. (2013). Adherence to and consumption of nicotine replacement therapy and the relationship with abstinence within a smoking cessation trial in primary care. Nicotine. Tob. Res. 15, 1537-1544

Hughes, J. R., Hatsukami, D. (1986). Signs and symptoms of tobacco withdrawal. Arch. Gen. Psychiatry, 43, 289-94.

Jha, P., Chaloupka, F. J., Moore, J. (2006). Tobacco addication. In: Jamison, D.T., Breman, J.G.,Measham, A.R. Disease Control Priorities in Developing Countries. Washington, DC, New York, NY: Oxford University Press and World Bank, pp. 869-886.

Klesges, R. C., Brown, K., Pascale, R. W., Murphy, M., Williams, E., Cigrang, J. A. (1988). Factors associated with participation, attrition, and outcome in a smoking cessation program at the workplace. Health Psychol, 7, 575-89

Kopjar, B., Sales, A. E., Piñeros, S. L., Sun, H., Li, Y. F., Hedeen, A. N. (2003). Adherence with statin therapy in secondary prevention of coronary heart disease in veteran's administration male population. Am. J. Cardiol, 92, 1106-1108.

Maziak, W. (2014). The waterpipe: a new way of hooking youth on tobacco. Am.J.Addict, 23, 103-107.

Maziak, W., Eissenberg, T., Klesges, R. C., Keil, U., Ward, K. D. (2004). Adapting smoking cessation interventions for developing countries: a model for the Middle East. Int. J. Tuberc. Lung Dis. 8, 403-413.

Maziak, W. (2006). Health in the Middle East. BMJ, 333, 815-816.

Mizes, J. S., Sloan, D. M., Segraves, K., Spring, B., Pingitore, R., Kristeller, J. (1998). The influence of weight-related variables on smoking cessation. Behav. Ther. 29, 371-385.

Nachega, J. B., Hislop, M., Dowdy, D. W., Lo, M., Omer, S. B., Regensberg, L., Chaisson, R.E., Maartens, G. (2006). Adherence to highly active antiretroviral therapy assessed by pharmacy claims predicts survival in HIV-infected South African adults. J. Acquir. Immune Defic. Syndr, 43, 78-84.

Okuyemi, K. S., Zheng, H., Guo, H., Ahluwalia, J. S. (2010). Predictors of adherence to nicotine gum and counseling among African-American light smokers. J Gen. Intern. Med, 25, 969976.

Patterson, F., Jepson, C., Kaufmann, V., Rukstalis, M., Audrain-McGovern, J., Kucharski, S., Lerman, C. (2003). Predictors of attendance in a randomized clinical trial of nicotine replacement therapy with behavioral counseling. Drug alcohol depend, 72, 123-131.

Post, A., Gilljam, H., Rosendahl, I., Bremberg, S., Rosaria Galanti, M. (2010). Symptoms of nicotine dependence in a cohort of Swedish youths: a comparison between smokers, smokeless tobacco users and dual tobacco users. Addiction, 105, 740-746. 
Radloff L. D. (1977). The CES-D: a self-report depression scale for research in the general population. Appl. Psychol. Meas, 1, 385-401.

Ruddy, K. J., Partridge, A. H.(2009). Adherence with adjuvant hormonal therapy for breast cancer. Ann. Oncol, 20, 401-402.

Shiffman, S., Sweeney, C. T., Ferguson, S. G., Sembower, M. A., Gitchell, J. G. (2008). Relationship between adherence to daily nicotine patch use and treatment efficacy: secondary analysis of a 10 week randomized, double-blind, placebo-controlled clinical trial simulating over-the-counter use in adult smokers. Clin. Ther. 30, 1852-1858.

Stein, M., Cantrell, C., Sokol, M., Eaddy, M., Shah, M.. (2006). Antidepressant adherence and medical resource use among managed care patients with anxiety disorders. Psychiatr. Serv. 57, 673-680.

Thomas J. L., Jones G. N., Scarinci I. C., Mehan D. J., Brantley P. J. (2001). The utility of the CES-D as a depression screening measure among low-income women attending primary care clinics. The Center for Epidemiologic Studies-Depression. Int. J. Psychiatry Med. 31: $25-40$.

Timberlake, D. S. (2008). A latent class analysis of nicotine-dependence criteria and use of alternate tobacco. J. Stud. Alcohol Drugs 69, 709-717.

Tomar, S. L., Alpert, H. R., Connolly, G. N. (2010). Patterns of dual use of cigarettes and smokeless tobacco among US males: findings from national surveys. Tob.Control, 19, 104109.

Velicer W. F., Diclemente C. C., Rossi J. S., Prochaska J. O. (1990) . Relapse situations and selfefficacy: an integrative model. Addict. Behav. 15, 271-83.

Ward, K. D., Asfar, T., Al Ali, R., Rastam, S., Weg, M. W. V., Eissenberg, T., Maziak, W. (2013). Randomized trial of the effectiveness of combined behavioral/pharmacological smoking cessation treatment in Syrian primary care clinics. Addiction, 108, 394-403.

Ward, K. D., Eissenberg, T., Rastam, S., Asfar, T., Mzayek, F., Fouad, M. F., Hammal, F., Mock, J., Maziak, W. (2006). The tobacco epidemic in Syria. Tob. Control, 15 (suppl 1), i24-i29.

World Bank., (2010). Tobacco Control at glance. Available at: http://siteresources.worldbank.org/INTPH/Resources/3760861238076532997/TobaccoControl2010Nov15.pdf (Accessed January 14th, 2015)

World Health Organization (WHO). (2010). FCTC/COP4(8): Guidelines for Implementation of Article 14 of the WHO Framework Convention on Tobacco Control. Available at:http://www.who.int/fctc/protocol/guidelines/adopted/article_14/en/index.html (accessed on 17 December, 2014) 
World Health Organization. (2013a). Report on the Global Tobacco Epidemic. The MPOWER Package. Available at: http://www.who.int/tobacco/global_report/2013/en/ (accessed on 2 December, 2014).

World Health Organization. (2013b). Report on the Global Tobacco Epidemic: country profile. Syrian Arab Republic. Available at:

http://www.who.int/tobacco/surveillance/policy/country_profile/syr.pdf (accessed on 22 April 2015).

Zimet, G. D., Dahlem, N. W., Zimet, S. G., Farley, G. K. (1988). The multidimensional scale of perceived social support. J. Pers. Assess, 52, 30-41.

Zimet, G. D., Powell, S. S., Farley, G. K., Werkman, S., Berkoff, K. A. (1990). Psychometric characteristics of the Multidimensional Scale of Perceived Social Support. J. Pers. Assess, $55,610-7$. 


\section{Tables and figures}

Table 1. Baseline characteristics by adherence to pharmacological and behavioral counseling in a cessation trial among smokers in Aleppo, Syria

\begin{tabular}{|c|c|c|c|c|c|c|}
\hline & \multicolumn{2}{|c|}{$\begin{array}{l}\text { 80\% Adherence to pharmacological } \\
\text { treatment }\end{array}$} & \multicolumn{4}{|c|}{ Adherence to behavioral counseling } \\
\hline & $\begin{array}{c}\text { Adherent } \\
(\mathrm{n}=183) \\
\text { mean }(\mathrm{SD}) \text { or } \\
\%\end{array}$ & $\begin{array}{c}\text { Non Adherent } \\
(\mathbf{n}=\mathbf{8 6}) \\
\text { mean (SD) or \% }\end{array}$ & $\begin{array}{c}\text { p- } \\
\text { value* }\end{array}$ & $\begin{array}{c}\text { Adherent } \\
(\mathbf{n}=187) \\
\text { mean (SD) or } \\
\%\end{array}$ & $\begin{array}{c}\text { Non Adherent } \\
(\mathrm{n}=\mathbf{8 2}) \\
\text { mean (SD) or \% }\end{array}$ & p-value* \\
\hline \multicolumn{7}{|l|}{ Demographics } \\
\hline age & $40.8(11.1)$ & $38.2(11.7)$ & 0.084 & $41.0(11.2)$ & $37.6(11.4)$ & 0.024 \\
\hline Gender (male \%) & 77.6 & 80.2 & 0.751 & 80.4 & 73.2 & 0.185 \\
\hline Education (years completed) & $10.3(4)$ & $10(4)$ & 0.648 & $10.3(3.8)$ & $10.2(4.6)$ & 0.938 \\
\hline Number of people in the house & $5.4(2.9)$ & $5(2.2)$ & 0.333 & $5.3(2.8)$ & $5.4(2.6)$ & 0.830 \\
\hline Marital status (Married \%) & 80.9 & 75.6 & 0.452 & 82.6 & 72 & 0.245 \\
\hline Religion (Muslim \%) & 72.7 & 79.1 & 0.381 & 73.9 & 76.8 & 0.596 \\
\hline \multicolumn{7}{|l|}{ Tobacco use } \\
\hline Treatment group (Nicotine \%) & 56.3 & 23.1 & 0.002 & 53.8 & 41.5 & 0.063 \\
\hline Amount smoked (cigarettes/day) & $26(11.7)$ & $31.4(14.1)$ & 0.001 & $26(11.4)$ & 31.3(14.3) & 0.002 \\
\hline Age when smoked first cigarette & $19(5.3)$ & $17.7(5.2)$ & 0.049 & $18.8(5.3)$ & $18.3(5.2)$ & 0.526 \\
\hline Readiness to quit score $^{\mathrm{a}}$ & $7.9(0.9)$ & $7.6(1.1)$ & $\mathbf{0 . 0 3 3}$ & $7.9(0.9)$ & $7.6(0.9)$ & 0.027 \\
\hline Fagerstrom Test of Nicotine Dependence ${ }^{b}$ & $5.5(2.2)$ & $6.1(2.2)$ & 0.041 & $5.5(2.2)$ & $6.1(2)$ & 0.060 \\
\hline Confidence in ability to quit ${ }^{\mathrm{C}}$ & $6.9(2.4)$ & $6.9(2.5)$ & 0.950 & $6.9(2.2)$ & $6.8(2.6)$ & 0.698 \\
\hline Carbon monoxide (p.p.m.) & 27.4(17.1) & 27.8(13.9) & 0.822 & $28(17.1)$ & $26.2(13)$ & 0.404 \\
\hline Tobacco withdrawal symptoms score & 27.3 & 32.4 & 0.036 & 27.2 & 32.9 & 0.022 \\
\hline Water pipe use $(\%)$ & 7.1 & 18.6 & 0.005 & 9.2 & 14.6 & 0.192 \\
\hline Perception of treatment (placebo \%) & 30.1 & 62.3 & $<0.001$ & 30.4 & 61.8 & $<0.001$ \\
\hline \multicolumn{7}{|l|}{ Psychosocial } \\
\hline Social support ${ }^{\mathrm{d}}$ & $20.7(11.8)$ & $18.9(11.4)$ & 0.240 & 20.1(11.7) & $19.6(11.5)$ & 0.950 \\
\hline Depressions (CES-D) score ${ }^{\mathrm{e}}$ & $17.6(10.5)$ & $18.8(9.1)$ & 0.358 & $17.5(10.1)$ & $19.4(10.2)$ & 0.145 \\
\hline
\end{tabular}


Table 2. Predictors of adherence to pharmacologic treatment and behavioral counselling in a cessation trial among smokers in Aleppo, Syria determined by logistic regression

\begin{tabular}{|c|c|c|c|}
\hline Adherence to pharmacologic treatment & $\mathbf{O R}$ & CI $(95 \%)$ & P-value \\
\hline \multicolumn{4}{|l|}{ Treatment group } \\
\hline Nicotine & 2.52 & $1.37-4.78$ & 0.003 \\
\hline Placebo & Ref & & \\
\hline \multicolumn{4}{|l|}{ Water-pipe use } \\
\hline Non-smoker & 4.25 & $1.61-11.1$ & 0.004 \\
\hline Smoker & Ref & & \\
\hline Total withdrawal symptoms score & 0.97 & $0.95-0.98$ & 0.003 \\
\hline Cigarettes per day & 0.97 & $0.94-0.99$ & 0.014 \\
\hline \multicolumn{4}{|l|}{ Perception of treatment allocation } \\
\hline Nicotine & 4.31 & $2.29-9.31$ & $<0.001$ \\
\hline Placebo & Ref & & \\
\hline Adherence to behavioral counselling & OR & CI $(95 \%)$ & P-value \\
\hline \multicolumn{4}{|l|}{ Gender } \\
\hline Male & 2.41 & $1.21-4.94$ & 0.017 \\
\hline Female & Ref & & \\
\hline Total withdrawal symptoms score & 0.98 & $0.96-0.99$ & 0.015 \\
\hline Cigarettes per day & 0.97 & $0.94-0.98$ & 0.021 \\
\hline \multicolumn{4}{|l|}{ Perception of treatment allocation } \\
\hline Nicotine & 4.61 & $2.41-8.84$ & $<0.001$ \\
\hline Placebo & Ref & & \\
\hline
\end{tabular}

Note. $\mathrm{CI}=$ confidence interval; $\mathrm{OR}=$ odds ratio. 


\title{
MANUSCRIPT 2
}

(C) Copyright 2016

Ben Taleb, Z., Ward, K.D, Asfar, T., Jaber, R., Auf, R., Maziak, W. (2016). Predictors of nicotine withdrawal symptoms: findings from the first randomized smoking cessation trial in a lowincome country setting. International Journal of Public Health.1-8. [Epub ahead of print]

\begin{abstract}
Background: Inability to cope with withdrawal symptoms when attempting to quit is a major cause for failure of cessation. However, little is known about factors influencing nicotine withdrawal symptoms in low-income countries. Aim: To identify predictors of nicotine withdrawal symptoms among smokers who participated in a randomized cessation trial in a low-income country. Methods: We analyzed data from 269 smokers who participated in a randomized, placebocontrolled smoking cessation trial conducted in primary healthcare in Aleppo, Syria. All participants received behavioral counseling and were randomized to receive either 6 weeks of nicotine or placebo patch and were followed for one year. Results: Throughout the study, lower total withdrawal score was associated with greater education $(p=0.044)$, older age of smoking initiation $(p=0.017)$, lower nicotine dependence $(p=0.024)$, higher confidence in ability to quit $(p=0.020)$, lower reported depression $(p<0.001)$, higher adherence to patch $(p=0.026)$, belief of receiving nicotine patches rather than placebo $(p=0.011)$, and waterpipe use $(p=0.047)$. Conclusion: Lower nicotine dependence, greater educational attainment, waterpipe use and higher confidence in ability to quit predict lower withdrawal severity among participants in a smoking cessation intervention in a low-income country setting. Further, expectancies about the effects of pharmacotherapy appear to mediate the experience of nicotine withdrawal.
\end{abstract}

KEYWORDS: nicotine, withdrawal, cessation, smoking, low-income countries 


\section{Introduction}

The need for tobacco cessation interventions in low-income developing countries is evident, particularly in countries where tobacco consumption is high and represents a major health problem (Ward et al., 2006; World Health Organization, 2011). The spread of heavy smoking combined with lack of tested cessation programs makes quitting more challenging for smokers in those countries (Maziak et al., 2014). Quitting smoking is known to be difficult, even when aided with pharmacological and behavioral therapies (Ray et al., 2009). In fact, especially among chronic users, smoking cessation results in unpleasant physiological and psychological symptoms collectively known as Nicotine Withdrawal Syndrome. This syndrome is a central constituent of tobacco dependence (Hughes et al., 1990). It includes a combination of subjective, cognitive, and physiological symptoms that manifest when a smoker tries to quit. These symptoms hinder efforts to stop and maintain long-term abstinence from smoking (Shiffman et al., 2004); therefore, the inability to cope with withdrawal symptoms when quitting seems to account for a large number of failed cessation attempts (West et al., 1989).

Although accomplishing complete abstinence from smoking is the ultimate goal of cessation efforts, nicotine withdrawal symptoms are also of a great interest for two reasons. First, withdrawal symptoms have a substantial role in inducing smoking relapse that compromises cessation outcomes (Shiffman et al., 2004). In fact, several studies show that the pattern, duration, and severity of withdrawal symptoms experienced during cessation attempts are important predictors of abstinence among smokers (Allen et al., 2008; Hughes, 2007; Piasecki et al., 2003). Second, withdrawal symptoms are considered clinically significant as they cause discomfort and distress among smokers who are trying to quit. Therefore, closer examination of the individual characteristics that could influence the intensity of nicotine withdrawal symptoms is necessary to improve our understanding and management of these symptoms (Shiffman et al., 2004). 
Prior research highlighted some of the important factors influencing nicotine withdrawal symptoms. These include smokers' baseline serum cotinine levels (measure of nicotine levels), number of cigarettes smoked per day, motivation to smoke, and depression (Morrell et al., 2008; West and Russell, 1985). Despite the extensive literature on evaluating nicotine withdrawal symptoms in populations from high-income countries (Bidwell et al., 2013; Gritz et al., 1991; Hendricks and Leventhal, 2013; Hendricks et al., 2014; Morrell et al., 2008; Neiro et al., 2014; Piasecki et al., 2003; West and Russell, 1985; West et al., 2008), such information in low-income countries lags behind. Findings from the first cessation trial that was conducted in a low-income country setting (Aleppo, Syria), show that having fewer nicotine withdrawal symptoms during smoking cessation treatment was associated with a greater likelihood of smoking abstinence (Ward et al., 2013). Therefore, there is a great need for further examination of the nature of nicotine withdrawal symptoms, and individual factors (e.g., demographic, smoking related and psychosocial) that may influence the severity of these symptoms in low-income countries such as Syria, which as many other Middle Eastern countries has a different smoking profile in comparison to western developed high-income countries (Maziak et al., 2004).

This study aims to address this knowledge gap by investigating predictors of nicotine withdrawal symptoms among smokers who participated in a randomized cessation trial in a lowincome country (Syria). Our findings will provide insights about factors that influence nicotine withdrawal symptomology among smokers in the Syrian context, and will likely be useful for other developing countries in the Middle East that share similar cultural and tobacco use patterns.

\section{Methods}

$\underline{\text { Study design }}$

We analyzed data from a multi-site two-group, parallel-arm, double-blind, randomized, placebo-controlled trial that was conducted in four primary healthcare centers in Aleppo, Syria in 
2008. All Eligible and interested smokers received physician-delivered face-to-face behavioral counseling and brief telephone support, and then randomized to receive either active transdermal nicotine (TN) patches or placebo TN patches. A total of 269 smokers (age 18-65 years old), who had smoked $>5$ cigarettes/day for at least one year were recruited. Exclusion criteria were (i) a diagnosis of generalized dermatology disease, liver failure, hyperthyroidism or pheochromocytoma; (ii) current use of psychotropic drugs; (iii) past year history of drug or alcohol abuse; (iv) current unstable cardiovascular or psychiatric illness, or any other debilitating disease based on their physician's assessment; (v) currently pregnant, lactating or intending to become pregnant during the next three months. Participants were patients who resided within the catchment area of one of the four centers included in the study. Each center had a primary care physician who delivered the smoking cessation intervention, served as the study coordinator, and liaised between the centers' physicians and the research staff to ensure adherence to the study protocol. The study was approved by the Institutional Review Boards of The University of Memphis and Syrian Center for Tobacco Studies. Full details of the trial design and its methods are published elsewhere (Ward et al., 2013).

\section{Procedures and intervention delivery}

Patients who were interested in quitting were referred by their primary physician to the cessation coordinator. Upon referral, the cessation coordinator described the study, screened participants for eligibility, and obtained a written informed consent from them. Patients who were not interested and/or ineligible were provided with self-help materials and referred back to their original physician. After recruitment, participants completed a battery of baseline questionnaires including: demographic characteristics, smoking history (e.g., number of cigarettes smoked per day, level of dependence, previous quit attempt, interest in quitting), self-efficacy, stage of change, nicotine withdrawal symptoms, and depression/mood. Participants then were randomized using 
random permuted blocks stratified by clinic and gender to receive either behavioral counseling + active TN patches (active treatment group) or behavioral counseling + placebo TN patches (control group). The intervention delivered during six weeks, then participants were followed at end of treatment (6 weeks after quit date), and at 6- and 12-months.

Pharmacological Intervention

Patients in the nicotine group received a six-week supply of Nicotinell ${ }^{\mathrm{TM}}$ patches, 24-hour dose, using a step-down algorithm. Patients who smoked $\geq 10$ cigarettes/day received a 2 -week supply of 21-mg patches, then a 2-week supply of 14-mg patches, then a 2-week supply of 7-mg patches. Patients who smoked 5-9 cigarettes per day received a 4-week supply of 14-mg patches, then a 2-week supply of 7-mg patches. Patients in the placebo group received the same step-down algorithm. Placebo patches were provided by a local manufacturer and looked identical to the nicotine patches (Ward et al., 2013).

\section{$\underline{\text { Behavioral counseling }}$}

All patients received a culturally adapted behavioral smoking cessation intervention developed and tested in a pilot trial in the same population (Asfar et al., 2008; Fiore et al., 2008). Participants in both groups received the same intervention that includes three individual in-person sessions (approximately $30 \mathrm{~min}$ each) and five brief phone calls (approximately $10 \mathrm{~min}$ ).

$\underline{\text { Measures }}$

\section{Baseline variables}

Predictors that were assessed at baseline include: Socio-demographic characteristics (age, gender, marital status, number of people in the house, years of education and religion); smoking history (number of years as a cigarette smoker; age when daily smoking began, current amount smoked per day), waterpipe use and dose of the treatment for patch (high vs. low dosage scheme). 
Assessment of Motivation to quit was done using the Readiness to Quit Ladder (Biener and Abrams 1991), higher score represents greater levels of readiness to quit. The scale consist of 10 items and provides a continuous metric of motivation and/or readiness to quit. Confidence in ability to quit was also assessed using a 10 items continuous metric scale.

The Fagerström Test for Nicotine Dependence (FTND) was used for assessing the intensity of physical addiction to nicotine and it contains six items that evaluate the quantity of cigarette consumption, the compulsion to use, and dependence. (Heatherton et al., 1991).

\section{Time-varying variables}

The Multidimensional Scale of Perceived Social Support (MSPSS), was used to measure social support throughout the study. MSPSS is a brief research tool designed to measure perceptions of support from 3 sources: Family, Friends, and a Significant Other (Zimet et al., 1988).

Depressive symptomatology was assessed using the Center for Epidemiologic Studies Depression Scale (CES-D). The 20 items in CES-D scale is a self-report instrument composed of 20 items, and respondents are asked to rate how often they experienced symptoms (Sadness, Dysphoria, Loss of Interest, Appetite, Sleep, Thinking/ concentration, Guilt, Fatigued, Agitation and Suicidal ideation) of depression during the past week (Radloff, 1977). Participant's belief whether they had received active nicotine or placebo patches was measured using this question [Which patch do you think you have been using? nicotine or placebo]. Adherence to treatment (pharmacological and behavioral counseling) was assessed throughout the entire period of treatment (6 weeks).

\section{Nicotine Withdrawal Symptoms}

Nicotine withdrawal symptoms were assessed using the Minnesota Nicotine Withdrawal Scale (MNWS) (Hughes and Hatsukami, 1986) and was measured at baseline, session 2 (one week 
post-quit), session 3 (two weeks days post-quit), end of treatment (six weeks post-quit), and at the 6- and 12-month follow-up sessions. The mean of eight scale items (depression/feeling blue, difficulty concentrating, hunger, increased appetite, insomnia, irritability/ frustration/anger, restlessness, and anxiety), was calculated to obtain a total withdrawal score (Hughes and Hatsukami 1986,1998 ) and was measured on a range of possible values of 0 (not present) to 100 (most severe) for the past week.

\section{$\underline{\text { Statistical analysis }}$}

Descriptive statistics were used to examine participants' demographic and smoking history characteristics at baseline. The generalized estimating equation (GEE) procedure was used to assess the longitudinal effects of baseline and time varying variables on the total nicotine withdrawal score throughout the entire period of the study (from baseline through 12 months follow up). A separate model was built to assess early withdrawal symptoms (from baseline through six weeks post quit day). GEE allows to estimate the parameters of the generalized linear model with a possible unknown correlation between outcomes, accounts for time-dependent covariates, and allows for specifying the random and fixed effect (Zeger et al., 1988). We used a model that considered all variables of interest (complete model). Social support, depression and the perception of treatment allocation were modeled in GEE as time varying predictors (i.e., repeated measures analysis). All analyses were conducted using SPSS version 21 (SPSS Inc., Chicago, IL, USA). An alpha of 0.05 was used to define statistical significance.

\section{Results}

Males comprised $78 \%$ of the sample. The mean age of study participants was 39.9 years (Standard Deviation $[\mathrm{SD}]=11.4)$, with a mean of 10.2 years of education $(\mathrm{SD}=4.0)$. The mean number of cigarettes smoked per day was $27.7(\mathrm{SD}=12.7)$, while the mean age for starting daily smoking was 18.6 years $(\mathrm{SD}=5.3)$. The mean of Fagerström nicotine dependence score was 5.7 
$(\mathrm{SD}=2.2)$, while the mean for the total withdrawal score at baseline was $28.9(\mathrm{SD}=18.6)$. The two treatment groups (nicotine vs. placebo) did not differ significantly on any of the baseline characteristics (table 1).

Finding from the GEE linear regression, indicated that throughout the entire study period, lower total withdrawal score was associated with greater years of education $[\beta=-0.008(95 \% \mathrm{CI}=-$ $0.016,-0.001), p=0.044]$, older age of smoking initiation $[\beta=-0.006(95 \% \mathrm{CI}=-0.012,-0.001)$, $p=0.017]$, greater adherence to patch $[\beta=-0.090(95 \% \mathrm{CI}=-0.169,-0.011), p=0.026]$, smoking waterpipe at baseline $[\beta=-0.080(95 \% \mathrm{CI}=-0.596,-0.001), p=0.047]$ and higher confidence in ability to quit smoking $[\beta=-0.015(95 \% \mathrm{CI}=-0.027,-0.002), p=0.020]$. On the other hand, higher total withdrawal score was associated with greater baseline nicotine dependence $[\beta=0.021(95 \% \mathrm{CI}=$ $0.003,0.038), p=0.024]$, greater self-reported depression $[\beta=0.013(95 \% \mathrm{CI}=0.011,0.016)$, $p<0.001]$ and the belief that one had received placebo (not nicotine) patches $[\beta=0.065(95 \% \mathrm{CI}=$ $0.015,0.115$ ), $p=0.011$ ] (table 2). To assess predictors of early withdrawal severity during the duration of the treatment ( 6 weeks) we ran a secondary GEE analysis. Similar to the primary model, adherence to patch use $[\beta=-5.543(95 \% \mathrm{CI}=-9.817,-1.269), p=0.011]$, and greater self-reported depression $[\beta=0.401(95 \% \mathrm{CI}=0.211,0.592), p<0.001]$ was associated with higher withdrawal severity (table 3).

\section{Discussion}

This is the first study to examine predictors of nicotine withdrawal severity during smoking cessation trial in a low-income country. Throughout the study, lower total withdrawal score was associated with lower baseline nicotine dependence, higher confidence in ability to quit, lower depression, belief that one had received nicotine patch rather that placebo, greater years of education, older age of smoking initiation, greater adherence to patch, and waterpipe use. Our findings provide insight about factors that influence nicotine withdrawal symptomology among 
smokers undergoing cessation trial in a low-income country setting. The results of this study offer an important guide on the pattern and the severity of nicotine withdrawal symptoms and deliver valuable information for clinicians and researchers in designing tailored and effective cessation interventions in low-income countries.

Throughout the study, participants who reported higher confidence in the ability to quit at baseline experienced less severe nicotine withdrawal symptoms. Likely, this is because those who manifest higher confidence in ability to quit were more successful in maintaining abstinence and therefore experience less severe withdrawal. This finding emphasize the role of building confidence in self-ability to quit and strengthening self-efficacy prior to quit attempt to improve cessation outcomes (Nides et al., 1995).

It is also noteworthy, that waterpipe smoking at baseline was associated with less severe withdrawal symptoms throughout the study. It's possible that some smokers switch to waterpipe as substitute to cigarette during their quit attempt, which was also observed in a previous pilot behavioral cessation RCT from our team publication of our trial (Asfar et al., 2008). Additionally, qualitative evidence from the same population has shown that some cigarette smokers intentionally switch to waterpipe after quitting cigarettes to satisfy their craving for nicotine (Hammal et al., 2008). This highlight the fact that waterpipe smoking can serve as a barrier to smoking cessation efforts in countries where its use is highly prevalent.

On the other hand, more severe nicotine withdrawal symptoms were associated with younger age of smoking initiation, higher level of nicotine dependence at baseline and fewer years of education. However, there was no association between withdrawal severity and daily cigarette smoking at baseline. One might expect that heavier smokers at baseline would experience greater nicotine withdrawal severity throughout the study. Nevertheless, it should be noted that although withdrawal discomfort is related to loss of nicotine, it would not necessarily follow that it is also 
closely associated with the amount of daily cigarette consumption at baseline. This could be explained by the fact that levels of nicotine intake actually depend more on how the cigarettes are smoked than on the quantity of cigarettes being smoked. It is well known that smokers vary significantly in the amount they puff and inhale from their cigarettes; therefore, the measure of daily cigarette consumption at best only offers a crude guide to levels of nicotine intake (West and Russell 1985).

During the study, adherence to patch, regardless of whether it contained active nicotine or placebo, predicted less withdrawal. Similarly, the belief that one was assigned to active nicotine patch, regardless of actual assignment, predicted less withdrawal symptoms. In contrast, actual assignment to nicotine patch had no effect on withdrawal. Effects of expectancies appear to be specific to pharmacological treatment, because withdrawal severity was not predicted by adherence to behavioral counseling. Thus, expectancies about medication effects, rather than actual pharmacologic effect, seem to be a key mechanism in nicotine withdrawal relief in this sample. This has also been shown in previous studies, where expectations about receiving active nicotine rather than placebo was associated with less withdrawal symptoms, better cessation outcomes and greater adherence to cessation treatment (Dar et al., 2005; Darredeau et al., 2010; Taleb et al., 2015).

Our results lend further support to findings by Ward and colleagues (2013) that in a "real life" (primary care) setting in a low-income country, unlike most results from highly controlled cessation trials in high-income countries, nicotine patch may not offer much benefit for reducing withdrawal or promoting long term abstinence. However, the role of pharmacological therapy in decreasing withdrawal symptoms should not be underestimated. Certainly, the results of this trial need to be followed up in other populations and settings, to determine whether better control of withdrawal symptoms is possible pharmacologically. However, if this finding of limited utility for 
pharmacotherapy is confirmed in other studies, it would indicate the need to culturally adapt behavioral strategies to control withdrawal, such as coping skill training and educating quitters about the time course and cognitive vs. pharmacological determinants of withdrawal symptoms. A challenge to such an approach in countries such as Syria is the strong belief that medical consultations should result in a prescription for medication, together with the lack of familiarity/belief in behavioral treatment, and the belief that using medication is the most effective way to quit smoking (Asfar et al., 2008).

Another important finding of this study was the positive association between depression and withdrawal symptoms. This is in accordance with previous studies in high-income countries, which showed that depressed smokers appear to experience more severe withdrawal symptoms while quitting (Covey et al., 1990; Hall et al., 1992; Morrell et al., 2008), and therefore, they are less likely to be successful at their quitting attempts. Our results emphasize the role of depressed mood in predicting the intensity of the withdrawal syndrome in a low-income country setting, and the need to incorporate treatment for depression in smoking cessation programs (e.g., Shiffman et al., 2000).

This study comes with a few limitations. This is the first prospective study of nicotine withdrawal symptoms in a low-income country, but results may not generalize to other countries and treatment settings. Nonetheless, the similarity of many predictors of withdrawal between our study and others conducted in high-income countries supports the robustness and generalizability of our findings. Another point of consideration is that our results are based on self-reports of withdrawal symptoms; however, we employed a widely- accepted and reliable instrument for the assessment of nicotine withdrawal symptoms (Shiffman et al., 2004). Lastly, we did not collect information regarding passive smoking exposure at home or at work place. Therefore, we were not able to assess how it may influenced the severity of nicotine withdrawal symptoms in our study. 


\section{Conclusions}

In summary, our study shows that in a real world setting in a low-income country, the expectancy of an effect from patch, rather than the pharmacological effect of nicotine replacement per se, mediates the effect on withdrawal symptoms severity. Furthermore, greater confidence in ability to quit and waterpipe use at baseline were associated with less severe withdrawal symptoms. Additionally, similar to findings from high-income countries, more severe withdrawal symptoms were associated with higher nicotine dependence, younger age of initiation, lower education and greater self-reported depression. This knowledge will help in advancing the treatment of smoking dependence by informing intervention schemes so it targets important sources of withdrawal phenomena, and those likely to experience more withdrawal in low-income countries. Our findings deliver a guide on the pattern and the severity of nicotine withdrawal symptoms and provide valuable information for clinicians and researchers in designing tailored and effective cessation interventions in low-income countries.

\section{References}

Allen, S.S, Bade, T., Hatsukami, D., Center, B. (2008). Craving, withdrawal, and smoking urges on days immediately prior to smoking relapse. Nicotine Tob Res, 10: 35-45. doi: $10.1080 / 14622200701705076$.

Asfar, T., Vander Weg, M.W., Maziak, W., Hammal, F., Eissenberg, T., Ward, K.D. (2008). Outcomes and adherence in Syria's first smoking cessation trial. Am J Health Behav, 32: 146-156. doi: 10.5993/AJHB.32.2.4

Bidwell, L.C, Leventhal, A.M., Tidey, J.W., Brazil, L., Niaura, R.S., Colby, S.M. (2013). Effects of abstinence in adolescent tobacco smokers: Withdrawal symptoms, urge, affect, and cue reactivity. Nicotine Tob Res, 15:457-464. doi: 10.1093/ntr/nts155.

Biener, L., Abrams, D.B. (1991). The Contemplation Ladder: validation of a measure of readiness to consider smoking cessation. Health Psychol, 10: 360-365. doi: 10.1037//02786133.10.5.360

Covey, L.S., Glassman, A.H., Stetner, F. (1990). Depression and depressive symptoms in smoking cessation. Compr Psychiatry, 31: 350-354. doi:10.1016/0010-440X(90)90042-Q 
Dar R, Stronguin F, Etter JF. (2005). Assigned versus perceived placebo effects in nicotine replacement therapy for smoking reduction in Swiss smokers. J Consult Clin Psychol, 73: 350. doi:10.1037/0022-006X.73.2.350

Darredeau, C., Barrett, S.P,. (2011). The role of nicotine content information in smokers' subjective responses to nicotine and placebo inhalers. Hum Psychopharmacol, 25: 577581. doi: 10.1002/hup.1159.

Fiore, M.C., Jaen, C.R., Baker, T.B., et al. (2008). A clinical practice guideline for treating tobacco use and dependence: 2008 update. A US Public Health Service report. Am. J. Prev Med, 35: 158-76.

Gritz, E.R., Carr, C.R., Marcus, A.C. (1991).The tobacco withdrawal syndrome in unaided quitters. Br J Addict, 86: 57-69. doi: 10.1111/j.1360-0443.1991.tb02629.x

Hall, S.M, Muñoz, R.F, Reus, V.I., Sees, K.L. (1992). Nicotine, negative affect, and depression. J Consult Clin Psychol, 61: 761. doi: 10.1037/0022-006X.61.5.761

Hammal, F., Mock, J., Ward, K.D, Eissenberg, T., Maziak, W. (2008). A pleasure among friends: how narghile (waterpipe) smoking differs from cigarette smoking in Syria. Tob Control, 17:e3-e3.

Heatherton, T.F., Kozlowski, L.T., Frecker, R.C., Fagerstrom, K.O. (1991). The fagerstrom test for nicotine dependence: a revision of the fagerstrom tolerance questionnaire. $\mathrm{Br} \mathrm{J}$ Addict, 86: 1119-27. doi:10.1111/j.1360-0443.1991.tb01879.x

Hendricks, P.S., Delucchi, K.L., Benowitz, N.L., Hall, S.M. (2014). Clinical Significance of early Smoking Withdrawal effects and their relationships With Nicotine Metabolism: preliminary results from a pilot Study. Nicotine Tob Res, 16: 615-620. doi: $10.1093 /$ ntr/ntt204

Hendricks, P.S, Leventhal, A.M. (2013). Abstinence-related expectancies predict smoking withdrawal effects: implications for possible causal mechanisms. Psychopharmacology, 230: 363-373. doi: 10.1007/s00213-013-3169-7.

Hughes, J., Hatsukami, D. (1998). Errors in using tobacco withdrawal scale. Tob Control, 7: 92. doi:10.1136/tc.7.1.92a

Hughes, J.R. (2007) Effects of abstinence from tobacco: valid symptoms and time course. Nicotine Tob Res, 2007;9: 315-327. doi: 10.1080/14622200701188919

Hughes, J.R., Hatsukami, D. (1986). Signs and symptoms of tobacco withdrawal. Arch Gen Psychiatry, 43: 289-294. doi: 10.1001/archpsyc.1986.01800030107013.

Hughes, J.R., Higgins, S.T., Hatsukami, D.K,. (1990). Effects of abstinence from tobacco: A critical review. In Kozlowski LT, Annis HM, Cappell HD, et al.(Eds.). Research advances in alcohol and drug problems, 317-398. doi: 10.1007/978-1-4899-1669-3_10 
Maziak, W., Eissenberg, T., Klesges, R.C., Keil, U., Ward, K.D. (2004). Adapting smoking cessation interventions for developing countries: a model for the Middle East. The International Journal of Tuberculosis and Lung Disease, 8(4), 403-413.

Maziak, W., Nakkash, R., Bahelah, R., Husseini, A., Fanous, N., Eissenberg, T .(2014).Tobacco in the Arab world: old and new epidemics amidst policy paralysis. Health policy plan, 29: 784-794. doi: 10.1093/heapol/czt055.

Morrell, H.E., Cohen, L.M., Al'Absi, M. (2008). Physiological and psychological symptoms and predictors in early nicotine withdrawal. Pharmacol Biochem Behav, 89: 272-278. doi: 10.1016/j.pbb.2007.12.020.

Neiro, B.P., Durán, A.L., Del Río, E.F., Pradeda, Ú.M., Brandon, T.H., Iglesias, E.B. (2014). Craving and nicotine withdrawal in a Spanish smoking cessation sample. Adicciones, 26:230-237.

Nides, M.A., Rakos, R.F., Gonzales, D., Murray, R.P., Tashkin, D.P., Bjornson-Benson, W.M., et al. (1995). Predictors of initial smoking cessation and relapse through the first 2 years of the Lung Health Study. J Consult Clin Psychol, 63:60-69

Piasecki, T.M., Jorenby, D.E., Smith, S.S., Fiore, M.C., Baker, T.B. (2003). Smoking withdrawal dynamics: II. Improved tests of withdrawal-relapse relations. J Abnorm Psychol 112: 14.doi: 10.1037/0021-843X.112.1.14.

Radloff, L.D. (1977). The CES-D: a self-report depression scale for research in the general population. Appl Psychol Meas, 1: 385-401. doi: 10.1177/014662167700100306

Ray, R., Schnoll, R.A., Lerman, C. (2009). Nicotine dependence: biology, behavior, and treatment Annu Rev Med, 60: 247-260. doi: 10.1146/annurev.med.60.041707.160511.

Shiffman, S., Johnston, J.A., Khayrallah, M., et al. (2000). The effect of bupropion on nicotine craving and withdrawal. Psychopharmacology, 148: 33-40. doi:10.1007/s002130050022.

Shiffman, S., West, R.J., Gilbert, D.G. (2004). Recommendation for the assessment of tobacco craving and withdrawal in smoking cessation trials. Nicotine Tob Res, 6: 599-614. doi:10.1080/14622200410001734067.

Taleb, Z.B., Ward, K.D., Asfar, T., Bahelah, R., Maziak, W. (2015) Predictors of adherence to pharmacological and behavioral treatment in a cessation trial among smokers in Aleppo, Syria. Drug alcohol depend,153: 167-172.

Ward, K.D., Asfar, T., Al Ali, R., et al. (2013). Randomized trial of the effectiveness of combined behavioral/pharmacological smoking cessation treatment in Syrian primary care clinics. Addiction 108: 394-403. doi: 10.1111/j.1360-0443.2012.04048.x.

Ward, K.D., Eissenberg, T., Rastam, S., et al. (2006). The tobacco epidemic in Syria. Tob Control, 15: i24-i29. doi: 10.1136/tc.2005.014860. 
West, R., Baker, C. L., Cappelleri, J.C., Bushmakin, A.G. (2008) Effect of varenicline and bupropion SR on craving, nicotine withdrawal symptoms, and rewarding effects of smoking during a quit attempt. Psychopharmacology, 197(3): 371-377. doi: $10.1007 / \mathrm{s} 00213-007-1041-3$

West, R.J., Hajek, P., Belcher, M. (1989) Severity of withdrawal symptoms as a predictor of outcome of an attempt to quit smoking. Psychol Med, 19(04): 981-985. doi:10.1017/S0033291700005705.

West, R.J., Russell, M.A. (1985) Pre-abstinence smoke intake and smoking motivation as predictors of severity of cigarette withdrawal symptoms. Psychopharmacology, 87: 334336. doi: 10.1007/BF00432717

World Health Organization. (2011). WHO Report on the Global Tobacco Epidemic: Warning about the Dangers of Tobacco. Geneva. http://www.who.int/tobacco/global_report/2011/en/.Accessed March 12, 2015.

Zeger, S.L., Liang, K.Y, Albert, P.S. (1988) Models for longitudinal data: a generalized estimating equation approach. Biometrics, 44:1049-60. doi: 10.2307/2531734

Zimet, G.D., Dahlem, N.W., Zimet, S.G., Farley, G.K. (1988) The multidimensional scale of perceived social support. J Pers Assess, 52: 30-41. doi:10.1207/s15327752jpa5201_2. 


\section{Tables and figures}

Table.1 Baseline characteristics by treatment condition among cessation trial participants (Syria 2008)

\begin{tabular}{|c|c|c|c|}
\hline Variables* & Overall sample & Placebo & Nicotine \\
\hline Age & $39.9(11.4)$ & $40.0(11.4)$ & $39.9(11.4)$ \\
\hline Gender (male \%) & 78.4 & 81.5 & 75.4 \\
\hline Education(years completed) & $10.3(4)$ & $10.4(4.1)$ & $10.2(4.0)$ \\
\hline Number of people in the house & $5.3(2.7)$ & $5.3(2.5)$ & $5.4(2.6)$ \\
\hline Marital status (Married \%) & 79.2 & 81.5 & 76.9 \\
\hline Religion (Muslim \%) & 74.7 & 74.8 & 74.6 \\
\hline Amount smoked (cigarettes/day) & 27.7(12.7) & $27.4(11.5)$ & $28.1(13.9)$ \\
\hline Age when smoked at least one cigarette per day & $18.7(5.3)$ & $18.6(5.0)$ & $18.7(5.6)$ \\
\hline Readiness to quit score $^{\mathrm{a}}$ & $7.8(0.9)$ & $9.1(1.3)$ & $8.9(1.3)$ \\
\hline Fagerstrom Test of Nicotine Dependence ${ }^{b}$ & $5.7(2.2)$ & $5.6(2.1)$ & $5.9(2.3)$ \\
\hline Confidence in ability to quit ${ }^{\mathrm{c}}$ & $6.9(2.4)$ & $7.0(2.3)$ & $6.9(2.5)$ \\
\hline Social support $^{\mathrm{d}}$ & $43.1(10.2)$ & $44.8(8.9)$ & $41.0(11.2)$ \\
\hline Nicotine withdrawal symptoms ${ }^{\mathrm{e}}$ score & 28.9(18.9) & $28.4(17.9)$ & $29.5(19.4)$ \\
\hline Depressions (CES-D) score ${ }^{f}$ & $18.0(10.1)$ & $17.2(10.0)$ & $18.9(10.2)$ \\
\hline Water pipe use (\%) & 10.8 & 11.1 & 10.4 \\
\hline Carbon monoxide (p.p.m.) & $27.5(15.2)$ & $27.6(15.7)$ & $27.4(16.6)$ \\
\hline
\end{tabular}

*For continuous variables, a two-sample $t$ test evaluated differences in means. For dichotomous variables, a chi-square test evaluated differences in proportions. ${ }^{\mathrm{a}}$ Range of possible values for readiness to quit is $0-10 .{ }^{\text {b }}$ Range of possible values for the Fagerstrom Test of Nicotine Dependence is $0-10 .{ }^{C}$ Range of possible values for confidence in ability to quit is $0-10$. ${ }^{\mathrm{d}}$ Range of possible values for the social

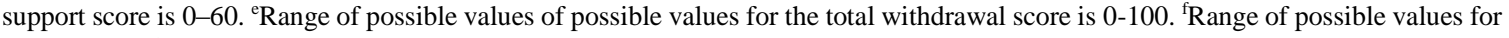
CES-D score is $0-60$ 
Table.2 Predictors of withdrawal symptoms from baseline to 12-month follow-up among cessation trial participants determined by generalized estimating equation (GEE) linear regression (Syria 2008)

\begin{tabular}{|c|c|c|c|}
\hline Variables & $\beta$ & $95 \% \mathrm{CI}$ & P-value ${ }^{f l}$ \\
\hline Age & -0.010 & $-0.023,0.002$ & 0.078 \\
\hline $\begin{array}{l}\text { Gender } \\
\text { Male } \\
\text { Female }\end{array}$ & $\begin{array}{l}0.070 \\
\text { Ref }\end{array}$ & $-0.003,0.142$ & 0.060 \\
\hline Education years & -0.008 & $-0.016,-0.001$ & 0.044 \\
\hline $\begin{array}{l}\text { Treatment } \\
\text { Nicotine } \\
\text { Placebo }\end{array}$ & $\begin{array}{c}-0.001 \\
\text { Ref }\end{array}$ & $-0.064,0.062$ & 0.981 \\
\hline $\begin{array}{l}\text { Dose of treatment (patch) } \\
\text { High } \\
\text { Low }\end{array}$ & $\begin{array}{l}-0.020 \\
\text { Ref }\end{array}$ & $-0.164,0.124$ & 0.785 \\
\hline Age when began smoking one cigarette per day & -0.006 & $-0.012,-0.001$ & 0.017 \\
\hline Total years of smoking at least one cigarette per day & -0.003 & $-0.006,0.001$ & 0.114 \\
\hline Amount smoked (Cigarettes/day) & -0.003 & $-0.007,0.001$ & 0.197 \\
\hline $\begin{array}{l}\text { Waterpipe use } \\
\text { Smoker } \\
\text { Non-smoker }\end{array}$ & $\begin{array}{c}-\mathbf{- 0 . 0 8 0} \\
\text { Ref }\end{array}$ & $-0.596,-0.001$ & 0.047 \\
\hline Fagerstrom Test of Nicotine Dependence & 0.021 & $0.003,0.038$ & 0.024 \\
\hline Motivation to quit (how motivated are you to quit) & -0.009 & $-0.032,0.014$ & 0.438 \\
\hline Confidence to quit (How confident are you that you can quit) & -0.015 & $-0.027,-0.002$ & $\mathbf{0 . 0 2 0}$ \\
\hline $\begin{array}{l}\text { Adherence to patch } \\
\text { Adherent } \\
\text { Non-Adherent }\end{array}$ & $\begin{array}{c}-\mathbf{0 . 0 9 0} \\
\text { Ref }\end{array}$ & $-0.169,-0.011$ & 0.026 \\
\hline $\begin{array}{l}\text { Adherence to behavioral counseling } \\
\text { Adherent } \\
\text { Non-adherent }\end{array}$ & $\begin{array}{l}0.010 \\
\text { Ref }\end{array}$ & $-0.081,0.101$ & 0.827 \\
\hline $\begin{array}{l}\text { Depression score* } \\
\text { Social support* }\end{array}$ & $\begin{array}{l}\mathbf{0 . 0 1 3} \\
0.001\end{array}$ & \begin{tabular}{r|}
$\mathbf{0 . 0 1 1 , 0 . 0 1 6}$ \\
$-0.001,0.004$
\end{tabular} & $\begin{array}{c}<\mathbf{0 . 0 0 1} \\
0.342\end{array}$ \\
\hline $\begin{array}{l}\text { Perception of treatment allocation* } \\
\text { Placebo } \\
\text { Nicotine }\end{array}$ & $\begin{array}{l}\mathbf{0 . 0 6 5} \\
\text { Ref }\end{array}$ & $0.015,0.115$ & 0.011 \\
\hline
\end{tabular}


Table 3. Predictors of withdrawal symptoms from baseline to end of treatment (6 weeks post quit day) among cessation trial participants determined by generalized estimating equation (GEE) linear regression (Syria 2008)

\begin{tabular}{|c|c|c|c|}
\hline Variables & $\beta$ & $95 \% \mathrm{CI}$ & P-value \\
\hline Age & -0.402 & $-0.895,0.091$ & 0.110 \\
\hline \multicolumn{4}{|l|}{ Gender } \\
\hline Male & 2.078 & $-3.016,7.172$ & 0.424 \\
\hline Female & Ref & & \\
\hline Education years & 0.083 & $-0.296,0.462$ & 0.668 \\
\hline \multicolumn{4}{|l|}{ Treatment } \\
\hline Nicotine & 1.568 & $-1.792,4.927$ & 0.360 \\
\hline Placebo & Ref & & \\
\hline \multicolumn{4}{|l|}{ Dose of treatment (patch) } \\
\hline High & 0.802 & $-5.473,7.078$ & 0.802 \\
\hline Low & Ref & & \\
\hline Age when began smoking one cigarette per day & 0.405 & $-0.080,0.890$ & 0.120 \\
\hline Total years of smoking at least one cigarette per day & 0.157 & $-0.396,0.710$ & 0.578 \\
\hline Amount smoked (Cigarettes/day) & -0.092 & $-0.328,0.143$ & 0.442 \\
\hline \multicolumn{4}{|l|}{ Waterpipe use } \\
\hline Smoker & -2.416 & $-7.707,2.874$ & 0.371 \\
\hline Non-smoker & Ref & & \\
\hline Fagerstrom Test of Nicotine Dependence & 0.273 & $-0.666,1.213$ & 0.568 \\
\hline Motivation to quit (how motivated are you to quit) & -0.321 & $-0.168,1.046$ & 0.645 \\
\hline Confidence to quit (How confident are you that you can quit) & -0.688 & $-1.436,0.060$ & 0.071 \\
\hline \multicolumn{4}{|l|}{ Adherence to patch } \\
\hline Adherent & -5.543 & $-9817,-1.269$ & 0.011 \\
\hline Non-Adherent & Ref & & \\
\hline \multicolumn{4}{|l|}{ Adherence to behavioral counseling } \\
\hline Adherent & -4.286 & $-10.37,1.803$ & 0.168 \\
\hline Non-adherent & Ref & & \\
\hline Depression score* & 0.401 & $0.211,0.592$ & $<0.001$ \\
\hline Social support* & 0.074 & $-0.071,0.218$ & 0.316 \\
\hline \multicolumn{4}{|l|}{ Perception of treatment allocation* } \\
\hline Placebo & 1.006 & $-2.484,4.495$ & 0.572 \\
\hline Nicotine & Ref & & \\
\hline
\end{tabular}




\title{
MANUSCRIPT 3
}

Smoking cessation and changes in Body Mass Index: findings from the first randomized cessation trial in low-income country setting

\begin{abstract}
Background: In high-income countries, quitting cigarette smoking is associated with weight gain, which can reduce motivation to abstain. Whether smoking cessation is associated with weight gain in a low-income country context has never been investigated. Aim: to determine the post-cessation changes in body mass index (BMI) and its predictors among smokers who received a smoking cessation intervention in a low-income country setting. Methods: We performed an ancillary analysis of data from 269 smokers who participated in a multi-site, two-group, parallel-arm, double-blind, randomized, placebo-controlled smoking cessation trial in primary care clinics in Aleppo, Syria. We used generalized estimating equation (GEE) modeling to identify predictors of changes in BMI at 6 weeks, 6- and 12-month follow-ups after quit date. Results: The mean precessation BMI of the sample was $27.9 \mathrm{~kg} / \mathrm{m}^{2}(S D=5.2)$. Smoking abstainers had 1.8 BMI units (approximately $4.8 \mathrm{~kg}$ ) greater than non-abstainers over one year post quitting $(P=0.012)$. Throughout the study, higher BMI was associated with being female $(P=0.048)$, reporting smoking to control weight $(P<0.001)$ and having previously failed to quit due to weight gain $(P=0.036)$. Conclusion: Similar to findings from high-income countries, smoking cessation in Syria is associated with weight gain, particularly among women and those who have weight concerns prior to quitting. This group of smokers may benefit from tailored cessation interventions with integrated body weight management elements that take into consideration the prevailing local and cultural influences on diet and levels of physical activity.
\end{abstract}

KEYWORDS: weight gain, post-cessation, smoking, BMI, developing countries 


\section{Introduction}

While quitting smoking improves health, several barriers may impede willingness to quit and ability to maintain abstinence. One of the most cited causes of failure to quit smoking is the fear of post-cessation weight gain (Jeffery et al., 2000; Perkins, 1993). Concerns related to weight gain following smoking cessation may discourage smokers from making a quit attempt (Pomerleau et al., 2001), and post-cessation weight gain may trigger relapse (Pisinger \& Jorgensen, 2007).

The relationship between smoking cessation and weight gain is well established (Ward et al., 2001). On average, smokers tend to weigh less than never smokers, and former smokers weigh more than current smokers (Flegal et al., 1995; Travier et al., 2009). Findings from prospective studies indicate that smoking cessation produces an average weight gain of 4-5 kg (Aubin et al., 2012; Eisenberg \& Quinn, 2006; Klesges et al., 1997, 1998; Lycett et al., 2011; Williamson et al., 1991) and a body mass index (BMI) increase of around $1.6 \mathrm{~kg} / \mathrm{m}^{2}$ after one year of abstinence (Munafò et al 2009; Owen-Smith \& Hannaford, 1999).

Evidence from high-income countries has documented several factors associated with postcessation weight gain. These include younger age (Wane et al., 2010), female gender (Williamson et al 1991), low socioeconomic status (Swan and Carmelli, 1995), lower baseline weight, nicotine dependence, and sedentary lifestyle (Hall et al., 1986). Moreover, using nicotine replacement therapy (NRT) reduces weight gain during the treatment; however, this effect is not maintained during long-term abstinence (Farley et al., 2012).

Prevalence and predictors of post-cessation weight gain may be different in low income compared to high income countries, since many risk factors differ. For example, Syrian smokers tend to be heavy smokers and nicotine dependent, and many also smoke waterpipes, factors which are usually associated with increased weight and obesity (Williamson et al., 1991; Shafique et al., 2012; Ward et al., 2014). On the other hand, people living in low-income countries may be less 
concerned about weight gain and have different rates of obesity than those living in high-income countries probably due to differences in socioeconomic status, and cultural and life style factors such as level of physical activity and diet choices (Badran and Laher, 2011; Fouad et al., 2006). To the best of our knowledge, no previous study evaluated weight gain by smokers treated with a combination of pharmacological and behavioral cessation treatment in low-income countries. The main objective of the present study is to determine predictors of post-cessation changes in BMI among smokers who participated in a smoking cessation intervention in a low-income country setting (Ward et al., 2013).

\section{Methods}

\section{$\underline{\text { Study design }}$}

This study utilized data from a multi-site, two-group, parallel-arm, double-blind, randomized, placebo-controlled trial conducted in primary care clinics in Aleppo, Syria in 2008. Smokers who were interested and eligible to participate in the study were randomized to receive either behavioral cessation counseling + active transdermal nicotine patches $(\mathrm{TN})$, or behavioral cessation counseling + placebo TN. A total of 269 smokers (18-65 years old) who had smoked at least 5 cigarettes/day for at least one year were recruited. Exclusion criteria included (1) a diagnosis of generalized dermatology disease, liver failure, hyperthyroidism or pheochromocytoma; (2) current use of psychotropic drugs; (3) past year history of drug or alcohol abuse; (4) current unstable cardiovascular or psychiatric illness, or any other debilitating disease based on their physician's assessment; (5) currently pregnant, lactating or intending to become pregnant during the next three months. Participants were patients who lived in Aleppo, and were registered at one of the four primary care clinics that were included in the study. These clinic provided cost free health care, and most of the patents attending these clinics have low socioeconomic status. Each clinic had a primary care physician who functioned as a cessation coordinator. The cessation coordinator 
liaised between other physicians and clinic-staff to ensure adherence to the study protocol, and delivered the intervention to the participants. Full details of the trial and its methods are published elsewhere (Ward et al., 2013).

\section{Procedures}

At the baseline assessment, participants provided demographic data, smoking related information (e.g., smoking history, level of dependence, waterpipe use, number of cigarettes smoked per day) and concerns regarding weight gain. Participants were then assigned to one of two treatment conditions [Arm A $(n=134)$ : behavioral counseling + active TN vs. Arm B $(n=135)$ : behavioral counseling + placebo $\mathrm{TN}$ ] using random permuted blocks, stratified by clinic and gender. After quit date, participants received 3 follow-up assessments and completed additional questionnaires to assess adherence to cessation treatment, withdrawal symptoms, and depression/mood.

Patients in the active treatment group received a six-week supply of Nicotinell ${ }^{\mathrm{TM}}$ patches, 24-h dose, using a step-down algorithm. Patients in the placebo group received the same step-down algorithm. Placebo patches were provided by a local manufacturer (Asfar et al., 2016). Additionally, all patients received physician-delivered face-to-face behavioral counseling and brief telephone support, using approaches shown to be effective in developed countries (Fiore et al., 2008) and adapted for the local Syrian culture based on pilot work (Asfar et al., 2008). Three individual, in-person sessions (approximately 30-min each) and 5 brief (approximately 10-min) phone calls, were delivered by the cessation interventionists. 
$\underline{\text { Measures }}$

\section{Baseline variables}

Socio-demographic characteristics (age, gender, density index, years of education); smoking-related variables (number of years as a cigarette smoker; onset of daily smoking, number of cigarettes smoked per day, waterpipe use). Weight concern at baseline was assessed using a variable reflecting smoking to control weight "I smoke to control weight" adapted from the Smoking Situations Questionnaire (Weekly et al., 1992), which was recoded as binary. [0=No, $1=$ Yes]. Previous failed attempts to quit due to weight gain was assessed by responding $[0=$ No, $1=$ Yes] to the statement "I have been unsuccessful in my past attempts to quit because of weight gain”. The Fagerström Test for Nicotine Dependence (FTND) was used for assessing the intensity of physical addiction to nicotine (Heatherton et al. 1991).

\section{Time varying variables}

The following factors were assessed at end of treatment (6 weeks post quit), 6- and 12months follow ups: Depressive symptomatology was assessed using the Center for Epidemiologic Studies Depression Scale (Radloff 1977), while abstinence from smoking (7 day point-prevalence abstinence defined as self-report of not smoking in the past 7 days and verified by exhaled carbon monoxide levels of $<10 \mathrm{ppm}$ ). Overall adherence to treatment (nicotine patch and behavioral counseling) was assessed throughout the entire period of treatment (every week for 6 weeks) (Taleb et al., 2015).

\section{Study outcome}

The main outcome was body mass index (BMI). Weight was measured to the nearest 0.1 $\mathrm{kg}$ using a digital scale equipped with a high-precision strain gauge sensor, and height was 
measured to the nearest $\mathrm{cm}$ using a portable stadiometer. We divided the body weight (in $\mathrm{kg}$ ) by the body height (in $\mathrm{m}^{2}$ ) to calculate the BMI (Ward et al., 2014).

\section{$\underline{\text { Statistical analysis }}$}

Descriptive statistics for the baseline characteristics of the study sample were summarized with means and standard deviations (SD) or proportions. Means and SDs for weight, BMI, waist circumference and changes in weight and BMI were summarized and compared across abstinence status at 6 weeks, and 6- and 12-month follow-ups. Differences in continuous variables were analyzed with the two- sample t- test, or with the Mann- Whitney test as appropriate. All variables of interest were checked for collinearity using the variance inflation factor (VIF). The generalized estimating equation (GEE) procedure was used to assess the longitudinal effects of baseline and time varying variables on BMI measurements throughout the entire period of the study. GEE allows estimation of the parameters of generalized linear model with a possible unknown correlation, accounts for time-dependent covariates, and allows for specifying random and fixed effects (Zeger et al. 1988). Model building followed the methods described by (Reed and Kass, 2010; Hardin \& Hilbe, 2003), and the goodness of fit was assessed using the quasi likelihood under independence model criterion (QIC) (Hardin \& Hilbe, 2003). The analyses were adjusted by age and gender and were conducted using SPSS version 21 (SPSS Inc., Chicago, IL, USA). An alpha of 0.05 was used to define statistical significance.

\section{Results}

Among the 269 participants at baseline, males comprised $78 \%$ of the sample. The mean age of study participants was 39.9 years (Standard Deviation $[\mathrm{SD}]=11.4$ ), with a mean of 10.2 years of education $(\mathrm{SD}=4.0)$. The mean number of cigarettes smoked per day was $27.7(\mathrm{SD}=12.7)$, while the mean age for starting daily smoking was 18.6 years $(\mathrm{SD}=5.3)$ and the mean Fagerström nicotine dependence score was $5.7(\mathrm{SD}=2.2)$. Mean weight was $80.3 \mathrm{Kg}(\mathrm{SD}=16.2)$, mean $\mathrm{BMI}$ 
was $27.9 \mathrm{Kg} / \mathrm{m}^{2}(\mathrm{SD}=5.2)$ and mean waist circumference was $95.7(\mathrm{SD}=12.5)$. Other baseline characteristics of the sample are summarized in table 1.

Table 2 presents mean values of weight, waist circumference, BMI and changes in weight and BMI at different time points of the study by abstinence status. Compared with non-abstainers, smoking abstainers gained significantly more weight at 6 weeks, 6- and 12-month follow-ups, and had greater BMI and greater waist circumference at the 6- and 12-month follow ups.

Findings from the GEE linear regression model (Table 3) indicated that throughout the entire study period, higher BMI was associated with: being abstinent from smoking $[\beta=1.869(95 \% \mathrm{CI}=0.405$, 3.333) $\mathrm{p}=0.012]$, having weight concerns at baseline (smoking to control weight) $[\beta=2.587$ $(95 \% \mathrm{CI}=1.314,3.859) \mathrm{p}<0.001]$, being female $[\beta=2.172(95 \% \mathrm{CI}=0.023,4.321) \mathrm{p}=0.048]$, and attributing past failed quit attempts to weight gain $[\beta=2.461(95 \% \mathrm{CI}=0.159,4.762) \mathrm{p}=0.036]$.

Being assigned to active nicotine treatment and adherence to cessation treatment were not significantly associated with BMI, nor was there a significant interaction between treatment condition and adherence to treatment. Furthermore, gender $\times$ abstinence status, gender $\times$ weight concerns and waterpipe smoking $\times$ abstinence status interactions terms were also not significant in the multivariable model (all p-values>0.05).

\section{Discussion}

This is the first study to examine BMI change and its predictors among smokers who attempted to quit smoking in a low-income country setting. Smoking abstainers experienced an average weight increase of $4.8 \mathrm{~kg}$ over a one year follow-up. Throughout the study, higher BMI was associated with abstinence from smoking, reporting smoking to control weight at baseline, failure to quit in the past due to weight gain, and being female. This information provide insight about factors that influence weight changes among smokers attempting to quit in a low-income 
country setting and will help in identifying smokers who are at higher risk of gaining weight postcessation.

Consistent with findings from high-income countries, our study shows that participants who maintained abstinence from smoking experienced an increase of $1.8 \mathrm{Kg} / \mathrm{m}^{2}$ more than nonabstainers. For an adult of average height in Syria (161.4 cm; Fouad et al., 2006) this BMI difference translates to $4.8 \mathrm{~kg}$ (10.5 lbs.) of body weight. Our findings are in line with other studies reporting that most quitters gain about $4-5 \mathrm{~kg}$ in the first year (Aubin et al., 2012) and around 1.6 $\mathrm{kg} / \mathrm{m}^{2}$ over the same time frame (Munafò et al., 2009; Owen-Smith \& Hannaford, 1999).

Several factors have been suggested to explain the post-cessation weight gain. These include an increase in caloric intake, a decrease in body metabolic rate (Filozof et al., 2004; Perkins, 1993) or a reduction in the role of physical activity (Perkins et al., 1989; Grunberg and Bowen, 1985). The weight reduction effect of nicotine usually occurs due to acute increases in resting metabolic rate along with an anorectic effect that reduces food intake (Ward et al., 2001). Therefore, when smokers quit, the loss of the metabolic enhancement and appetite suppression effect of nicotine lead to an increase in caloric intake that usually is not offset by increased physical activity. This positive energy imbalance consequently leads to weight gain (Audrain-McGovern and Benowitz 2011). In addition, our data shows that the most severe nicotine withdrawal symptoms experienced by abstainers were increased eating and hunger, which further contributes to increased caloric intake and weight gain (data not shown).

A systemic review that was done in 2012 to evaluate the effect of pharmacological treatment on post-cessation weight changes showed that NRT might prevent or at least attenuate weight gain (Farley et al., 2012). However, other investigations could not confirm this finding (Prod'hom et al., 2013; Allen et al., 2013). Similarly in our study, we found no association between being on active NRT (vs placebo) and changes in BMI post-quitting. In addition, we found no 
association between adherence to cessation treatment and changes in BMI. However, we did not provide other forms of pharmacological treatment such as varenicline, which based on recent evidence (Taniguchi et al., 2014) might be more effective in lessening post-cessation weight gain than NRT.

Similar to previous findings (Pisinger and Jorgensen, 2007), throughout the period of our study, women had higher BMI than men. The mechanism in which women gain more weight after quitting smoking is not yet well understood. However, it was previously shown that women are more concerned about their weight than men, and therefore, they may use smoking to suppress appetite or as a substitute to eating to stay in shape (French et al., 1994; Meyers et al., 1997). Further, numerous studies have shown that women experience higher energy intake postcessation than men leading to a greater weight gain (Levine et al., 2012; Ward et al., 2001; Nides et al., 1994; Klesges et al., 1990). In addition, women who live in low-income countries may have less active life style due to social restrictions. For example, in Syria, women are more often confined to their homes, either due to societal traditions or their pressing household duties and have probably less time and access to recreational and physical activities (Maziak, 2009).

Our results show that participants who reported failing in previous quit attempts due to weight gain or utilizing smoking as a way to control weight at baseline had higher BMI than those who did not. This is consistent with previous studies from high-income countries (Meyers et al., 1997; Pomerleau et al. 1993; Weekley et al. 1992). Evidence suggests that weight-control smokers have low efficacy in managing their food intake especially while dealing with negative emotions (Pinto et al., 1999). Using a combination of exercise, relaxation techniques and diet may help those smokers avoid overeating. It is also important that adjunct weight-control treatment or cognitive restructuring therapy regarding beliefs about weight control are incorporated into cessation programs to improve cessation rates. In fact, cognitive behavioral treatment designed to address 
weight concerns has been reported to increase rates of cessation and attenuate weight gain when compared with standard cessation programs (Perkins et al., 2001).

The present study has some limitations. The relationship between smoking cessation and weight gain is complex and multifactorial. There is likely a constellation of characteristics that is related to post-cessation weight gain such as higher levels of dietary intake and exercise behavior which we did not evaluate in our trial. Nevertheless, our results are in line with previous research from high-income countries, which further support the robustness of our findings, and point at some universal mechanisms governing weight gain in smoking cessation.

\section{Conclusions}

In summary, this is the first study to investigate post-cessation weight gain in a low-income country health care setting. A main result of our investigation is that similar to findings from highincome countries, smokers gain weight when they quit smoking, averaging $4.8 \mathrm{Kg}$ (10.5 lbs) over one year. Additionally, women, and those who reported smoking to control weight and having previously failed at quitting due to weight gain, were at increased risk for post-cessation weight gain. This information will provide insight for clinicians and researchers involved in program design and cessation efforts and will help in identifying those smokers who are at higher risk of weight gain after quitting. For these smokers, incorporating interventions that take into consideration the prevailing local and cultural influences on diet and levels of physical activity is recommended. Further research on the proportion of weight control smokers and how gender roles affect post-cessation weight gain in low-income countries is needed.

\section{References}

Allen, A. M., Kleppinger, A., Lando, H., \& Oncken, C. (2013). Effect of nicotine patch on energy intake and weight gain in postmenopausal women during smoking cessation. Eating behaviors, 14(4), 420-423. 
Asfar, T., Vander Weg, M.W., Maziak, W., Hammal, F., Eissenberg, T., Ward, K.D. (2008) Outcomes and adherence in Syria's first smoking cessation trial. Am J Health Behav, 32: 146-156. doi: 10.5993/AJHB.32.2.4

Asfar, T., Ward, K. D., Al-Ali, R., \& Maziak, W. (2016). Building evidence-based tobacco treatment in the eastern mediterranean region: Lessons learned by the syrian center for tobacco studies. Journal of Smoking Cessation, FirstView, 1-8. doi:10.1017/jsc.2016.5

Aubin, H. J., Farley, A., Lycett, D., Lahmek, P., \& Aveyard, P. (2012). Weight gain in smokers after quitting cigarettes: meta-analysis. BMJ, e4439

Audrain-McGovern, J., \& Benowitz, N. L. (2011). Cigarette smoking, nicotine, and body weight. Clinical Pharmacology \& Therapeutics, 90(1), 164-168

Badran, M., \& Laher, I. (2011). Obesity in Arabic-speaking countries. Journal of Obesity, 2011

Eisenberg, D., \& Quinn, B. C. (2006). Estimating the effect of smoking cessation on weight gain: an instrumental variable approach. Health services research, 41(6), 2255-2266.

Farley, A. C., Hajek, P., Lycett, D., \& Aveyard, P. (2012). Interventions for preventing weight gain after smoking cessation. Cochrane Database Syst Rev, 1.

Filozof, C., Pinilla, F., \& Fernández-Cruz, A. (2004). Smoking cessation and weight gain. Obesity reviews, 5(2), 95-103.

Fiore, M.C., Jaen, C.R., Baker, T.B., et al. (2008). A clinical practice guideline for treating tobacco use and dependence: 2008 update. A US Public Health Service report. Am. J. Prev Med 35: 158-76.

Flegal, K. M., Troiano, R. P., Pamuk, E. R., Kuczmarski, R. J., \& Campbell, S. M. (1995). The influence of smoking cessation on the prevalence of overweight in the United States. New England Journal of Medicine, 333(18), 1165-1170.

Fouad, M. F., Rastam, S., Ward, K. D., \& Maziak, W. (2006). Prevalence of obesity and its associated factors in Aleppo, Syria. Prevention and Control,2(2), 85-94.

French, S. A., Perry, C. L., Leon, G. R., \& Fulkerson, J. A. (1994). Weight concerns, dieting behavior, and smoking initiation among adolescents: a prospective study. American Journal of Public Health, 84(11), 1818-1820.

Grunberg, N. E., \& Bowen, D. J. (1985). The role of physical activity in nicotine's effects on body weight. Pharmacology Biochemistry and Behavior, 23(5), 851-854.

Hall, S. M., Ginsberg, D., \& Jones, R. T. (1986). Smoking cessation and weight gain. Journal of consulting and clinical psychology, 54(3), 342.

Hardin, J. W., \& Hilbe, J. M. (2003). Generalized estimating equations. John Wiley \& Sons, Inc. 
Heatherton TF, Kozlowski LT, Frecker, RC, Fagerstrom KO. (1991). The fagerstrom test for nicotine dependence: a revision of the fagerstrom tolerance questionnaire. $\mathrm{Br} J$ Addict, 86: 1119-27. doi:10.1111/j.1360-0443.1991.tb01879.x

Jeffery, R. W., Hennrikus, D. J., Lando, H. A., Murray, D. M., \& Liu, J. W. (2000). Reconciling conflicting findings regarding postcessation weight concerns and success in smoking cessation. Health Psychology, 19(3), 242.

Klesges, R. C., Eck, L. H., Clark, E. M., Meyers, A. W., \& Hanson, C. L. (1990). The effects of smoking cessation and gender on dietary intake, physical activity, and weight gain. International Journal of Eating Disorders,9(4), 435-445.

Klesges, R. C., Ward, K. D., Ray, J. W., Cutter, G., Jacobs Jr, D. R., \& Wagenknecht, L. E. (1998). The prospective relationships between smoking and weight in a young, biracial cohort: the Coronary Artery Risk Development in Young Adults Study. Journal of consulting and clinical psychology, 66(6), 987.

Klesges, R. C., Winders, S. E., Meyers, A. W., Eck, L. H., Ward, K. D., Hultquist, C. M., ... \& Shadish, W. R. (1997). How much weight gain occurs following smoking cessation: A comparison of weight gain using both continuous and point prevalence abstinence. Journal of consulting and clinical psychology, 65(2), 286.

Levine, M. D., Cheng, Y., Kalarchian, M. A., Perkins, K. A., \& Marcus, M. D. (2012). Dietary intake after smoking cessation among weight-concerned women smokers. Psychology of Addictive Behaviors, 26(4), 969.

Lycett, D., Munafò, M., Johnstone, E., Murphy, M., \& Aveyard, P. (2011). Associations between weight change over 8 years and baseline body mass index in a cohort of continuing and quitting smokers. Addiction, 106(1), 188-196.

Maziak, W. (2009). The crisis of health in a crisis ridden region. International Journal of Public Health, 54(5), 349-355.

Maziak, W., Eissenberg, T., Klesges, R. C., Keil, U., \& Ward, K. D. (2004). Adapting smoking cessation interventions for developing countries: a model for the Middle East. The International Journal of Tuberculosis and Lung Disease, 8(4), 403-413.

Meyers, A. W., Klesges, R. C., Winders, S. E., Ward, K. D., Peterson, B. A., \& Eck, L. H. (1997). Are weight concerns predictive of smoking cessation? A prospective analysis. Journal of consulting and clinical psychology, 65(3), 448.

Munafò, M. R., Tilling, K., \& Ben-Shlomo, Y. (2009). Smoking status and body mass index: a longitudinal study. Nicotine \& Tobacco Research, 11(6), 765-771.

Nides, M., Rand, C., Dolce, J., Murray, R., O'Hara, P., Voelker, H., \& Connett, J. (1994). Weight gain as a function of smoking cessation and 2-mg nicotine gum use among middle-aged smokers with mild lung impairment in the first 2 years of the Lung Health Study. Health Psychology, 13(4), 354. 
Owen-Smith, V., \& Hannaford, P. C. (1999). Stopping smoking and body weight in women living in the United Kingdom. Br J Gen Pract, 49(449), 989-990.

Perkins, K. A. (1993). Weight gain following smoking cessation. Journal of consulting and clinical psychology, 61(5), 768.

Perkins, K. A., Epstein, L. H., Marks, B. L., Stiller, R. L., \& Jacob, R. G. (1989). The effect of nicotine on energy expenditure during light physical activity. New England Journal of Medicine, 320(14), 898-903.

Perkins, K. A., Marcus, M. D., Levine, M. D., D'Amico, D., Miller, A., Broge, M., ... \& Shiffman, S. (2001). Cognitive-behavioral therapy to reduce weight concerns improves smoking cessation outcome in weight-concerned women.Journal of consulting and clinical psychology, 69(4), 604.

Pinto, B. M., Borrelli, B., King, T. K., Bock, B. C., Clark, M. M., Roberts, M., \& Marcus, B. H. (1999). Weight control smoking among sedentary women. Addictive Behaviors, 24(1), 75-86.

Pisinger, C., \& Jorgensen, T. (2007). Waist circumference and weight following smoking cessation in a general population: The Inter99 study. Preventive medicine, 44(4), 290295.

Pomerleau, C. S., Ehrlich, E., Tate, J. C., Marks, J. L., Flessland, K. A., \& Pomerleau, O. F. (1993). The female weight-control smoker: a profile. Journal of substance abuse, 5(4), 391-400.

Pomerleau, C. S., Zucker, A. N., \& Stewart, A. J. (2001). Characterizing concerns about postcessation weight gain: results from a national survey of women smokers. Nicotine \& Tobacco Research, 3(1), 51-60.

Prod'hom, S., Locatelli, I., Giraudon, K., Marques-Vidal, P., Clair, C., Bize, R., \& Cornuz, J. (2013). Predictors of weight change in sedentary smokers receiving a standard smoking cessation intervention. Nicotine \& Tobacco Research, 15(5), 910-916.

Radloff, L.D. (1977) The CES-D: a self-report depression scale for research in the general population. Appl Psychol Meas, 1: 385-401. doi: 10.1177/014662167700100306

Reed, J. L., \& Kaas, J. H. (2010). Statistical analysis of large-scale neuronal recording data. Neural Networks, 23(6), 673-684.

Shafique, K., Mirza, S. S., Mughal, M. K., Arain, Z. I., Khan, N. A., Tareen, M. F., \& Ahmad, I. (2012). Water-pipe smoking and metabolic syndrome: a population-based study. PloS one, 7(7), e39734.

Swan, G. E., \& Carmelli, D. (1995). Characteristics associated with excessive weight gain after smoking cessation in men. American Journal of Public Health, 85(1), 73-77. 
Taleb, Z. B., Ward, K. D., Asfar, T., Bahelah, R., \& Maziak, W. (2015). Predictors of adherence to pharmacological and behavioral treatment in a cessation trial among smokers in Aleppo, Syria. Drug and Alcohol Dependence, 153, 167-172.

Taniguchi, C., Tanaka, H., Nakamura, N., Saka, H., Oze, I., Ito, H., ... \& Sakakibara, H. (2014). Varenicline is more effective in attenuating weight gain than nicotine patch 12 months after the end of smoking cessation therapy: an observational study in Japan. Nicotine \& Tobacco Research, ntu045.

Travier, N., Agudo, A., May, A. M., Gonzalez, C., Luan, J. A., Besson, H., ... \& Boutron-Ruault, M. C. (2009). Smoking and body fatness measurements: A cross-sectional analysis in the EPIC-PANACEA study. Preventive Medicine, 49(5), 365-373.

Wane, S., Van Uffelen, J. G., \& Brown, W. (2010). Determinants of weight gain in young women: A review of the literature. Journal of Women's Health,19(7), 1327-1340.

Ward, K. D., Ahn, S., Mzayek, F., Al Ali, R., Rastam, S., Asfar, T., ... \& Maziak, W. (2014). The relationship between waterpipe smoking and body weight: population-based findings from Syria. Nicotine \& Tobacco Research, ntu121.

Ward, K. D., Asfar, T., Al Ali, R., Rastam, S., Vander Weg, M. W.., Eissenberg, T., \& Maziak, W. (2013). Randomized trial of the effectiveness of combined behavioral/pharmacological smoking cessation treatment in Syrian primary care clinics. Addiction, 108(2), 394-403.

Ward, K. D., Klesges, R. C., \& Vander Weg, M. W. (2001). Cessation of smoking and body weight. International Textbook of Obesity, 323-36.

Weekley, C. K., Klesges, R. C., \& Reylea, G. (1992). Smoking as a weight-control strategy and its relationship to smoking status. Addictive Behaviors, 17(3), 259-271.

Williamson, D. F., Madans, J., Anda, R. F., Kleinman, J. C., Giovino, G. A., \& Byers, T. (1991). Smoking cessation and severity of weight gain in a national cohort. New England Journal of Medicine, 324(11), 739-745.

Zeger, S. L., Liang, K. Y., \& Albert, P. S. (1988). Models for longitudinal data: a generalized estimating equation approach. Biometrics, 1049-1060. 


\section{Tables and figures}

Table.1 Baseline characteristics for the overall sample by treatment condition $(n=269)$.

\begin{tabular}{lc}
\hline Variables & Overall samp \\
\hline age & $39.9(11.4)$ \\
\hline Gender (male \%) & 78.4 \\
\hline Education (Years completed) & $10.2(4)$ \\
\hline Density Index $^{\mathrm{a}}$ & $1.5(0.9)$ \\
\hline Amount smoked (cigarettes/day) & $27.7(12.7)$
\end{tabular}

Age when smoked at least one cigarette per day 18.7(5.3)

Total years of smoking at least one cigarette per day 21.3(11)

\begin{tabular}{ll}
\hline Fagerstrom Test of Nicotine Dependence & $5.7(2.2)$
\end{tabular}

Nicotine withdrawal symptoms score $\quad 28.9(18.9)$

\begin{tabular}{lc}
\hline Depressions (CES-D) score $^{\mathrm{d}}$ & $18.0(10.1)$ \\
\hline Waterpipe use (\%) & 10.8 \\
\hline Carbon monoxide (p.p.m.) & $27.5(15.2)$ \\
\hline Weight $(\mathrm{Kg})$ & $80.3(16.2)$ \\
\hline BMI $\left(\mathrm{kg} / \mathrm{m}^{2}\right)$ & $27.9(5.2)$ \\
\hline Waist circumference $(\mathrm{cm})$ & $95.7(12.5)$
\end{tabular}

acalculated by dividing the number of people living in the house by the number of the rooms in the house. ${ }^{\mathrm{b}}$ Range of possible values for the Fagerstrom Test of Nicotine Dependence is 0-10. 'Range of possible values for total withdrawal discomfort score is $0-100$.

${ }^{\mathrm{d}}$ Range of possible values for CES-D score is $0-60$. 
Table.2 Mean weight, BMI, waist circumference, and change in weight by smoking status throughout the study

\begin{tabular}{|c|c|c|c|c|c|c|c|c|c|}
\hline & \multicolumn{2}{|c|}{$\begin{array}{l}\text { End of treatment } \\
\quad(6 \text { weeks) }\end{array}$} & \multicolumn{3}{|c|}{6 months } & \multicolumn{4}{|c|}{12 months } \\
\hline & $\begin{array}{l}\text { Abstinent } \\
(\mathrm{n}=69)\end{array}$ & $\begin{array}{c}\text { Non- } \\
\text { abstinent } \\
(\mathrm{n}=200)\end{array}$ & $\begin{array}{c}\text { p- } \\
\text { value* }\end{array}$ & $\begin{array}{l}\text { Abstinent } \\
(\mathrm{n}=45)\end{array}$ & $\begin{array}{c}\text { Non- } \\
\text { abstinent } \\
(\mathrm{n}=224)\end{array}$ & $\begin{array}{c}\text { p- } \\
\text { value* }\end{array}$ & $\begin{array}{l}\text { Abstinent } \\
(\mathrm{n}=47)\end{array}$ & $\begin{array}{c}\text { Non- } \\
\text { abstinent } \\
(\mathrm{n}=222)\end{array}$ & $\begin{array}{c}\mathrm{p}- \\
\text { value* }\end{array}$ \\
\hline Weight (kg) & $83.3(12.1)$ & $82.2(13.6)$ & 0.603 & $86.9(14.4)$ & $81.7(15.2)$ & 0.056 & $88.4(14.1)$ & $79.6(15.2)$ & 0.001 \\
\hline Waist circum $(\mathrm{cm})$ & $100.3(10.3)$ & $100.4(10.4)$ & 0.965 & 104.6(11.7) & $98.8(12.7)$ & 0.015 & $105.5(13.2)$ & $97.1(12.2)$ & $<0.001$ \\
\hline $\mathrm{BMI}\left(\mathrm{kg} / \mathrm{m}^{2}\right)$ & $29.4(5.3)$ & $28.3(4.5)$ & 0.182 & $30.6(5.8)$ & $28.1(4.8)$ & 0.007 & $31.3(5.5)$ & $27.5(4.7)$ & $<0.001$ \\
\hline $\begin{array}{l}\text { Changes in BMI } \\
\left(\mathrm{kg} / \mathrm{m}^{2}\right) \text { from baseline }\end{array}$ & $+0.90(1.2)$ & $+0.53(1.1)$ & 0.065 & $+1.4(1.6)$ & $-0.16(1.9)$ & $<0.001$ & $+1.4(1.8)$ & $+0.28(1.6)$ & $<0.001$ \\
\hline $\begin{array}{l}\text { Changes in weight } \\
(\mathrm{kg}) \text { from baseline }\end{array}$ & $+2.4(2.5)$ & $+1.4(2.9)$ & 0.035 & $+4.0(4.3)$ & $-0.2(3.8)$ & $<0.001$ & $+4.1(5.2)$ & $+0.8(3.4)$ & $<0.001$ \\
\hline
\end{tabular}


Table.3 Predictors of BMI changes from baseline to 12-month follow-up determined by generalized estimating equation (GEE) linear regression.

\begin{tabular}{|c|c|c|c|}
\hline Variables & $\boldsymbol{\beta}$ & $95 \% \mathrm{CI}$ & P-value \\
\hline \multicolumn{4}{|l|}{ Gender } \\
\hline Female & 2.172 & $0.023,4.321$ & 0.048 \\
\hline Male & Ref & & \\
\hline Age & 0.004 & $-0.220,0.228$ & 0.971 \\
\hline Years of education & 0.189 & $-0.063,0.442$ & 0.141 \\
\hline Density Index & 0.065 & $-0.667,0.797$ & 0.861 \\
\hline \multicolumn{4}{|l|}{ Treatment } \\
\hline Nicotine & 0.229 & $-1.127,1.585$ & 0.741 \\
\hline Placebo & Ref & & \\
\hline Amount smoked (Cigarettes/day) & 0.042 & $-0.030,0.114$ & 0.256 \\
\hline Fagerstrom Test of Nicotine Dependence & -0.207 & $-0.618,0.204$ & 0.324 \\
\hline Age when began smoking one cigarette per day & 0.039 & $-0.190,0.269$ & 0.737 \\
\hline Total years of smoking at least one cigarette per day & 0.028 & $-0.255,0.311$ & 0.845 \\
\hline \multicolumn{4}{|l|}{ Smoking to control weight } \\
\hline Yes & 2.587 & 1.314,3.859 & $<0.001$ \\
\hline No & Ref & & \\
\hline \multicolumn{4}{|l|}{ Waterpipe use } \\
\hline Smoker & -0.112 & $-2.878,2.654$ & 0.937 \\
\hline Non-smoker & Ref & & \\
\hline \multicolumn{4}{|l|}{ Adherence to patch } \\
\hline Adherent & -0.398 & $-2.641,1.846$ & 0.728 \\
\hline Non-Adherent & Ref & & \\
\hline \multicolumn{4}{|l|}{ Adherence to behavioral counseling } \\
\hline Adherent & -0.788 & $-2.927,1.352$ & 0.471 \\
\hline Non-adherent & Ref & & \\
\hline Depression score & -0.014 & $-0.074,0.047$ & 0.660 \\
\hline \multicolumn{4}{|l|}{ Abstinence status } \\
\hline Abstinence & 1.869 & $0.405,3.333$ & 0.012 \\
\hline Non Abstinence & Ref & & \\
\hline \multicolumn{4}{|l|}{ unsuccessful past quit attempts quit due to weight gain } \\
\hline Yes & 2.461 & $0.159,4.762$ & $\mathbf{0 . 0 3 6}$ \\
\hline No & Ref & & \\
\hline Total withdrawal score & -0.022 & $-0.060,0.016$ & 0.265 \\
\hline
\end{tabular}




\section{CONCLUSIONS}

This work provides the first comprehensive information regarding adherence to cessation treatment, nicotine withdrawal symptoms and post-cession weight gain among smokers who attempt to quit in a low-income developing country setting.

Our study suggests that adherence to cessation treatment for cigarette smokers in low-income countries such as Syria may benefit from integrated cessation components that provide intensive treatment for subjects with higher nicotine dependence, and address concurrent waterpipe use at all stages. Such novel insights on factors that influence adherence to cessation treatment in a developing country's setting, can help to improve cessation treatments for smokers living in countries at similar level of development.

In addition, this research shows that in a real world setting in a low-income country, the expectancy of an effect from patch, rather than the pharmacological effect of nicotine replacement per se, mediates the effect on withdrawal symptoms severity. Additionally, more severe withdrawal symptoms were associated with younger age of initiation, lower education and greater reported depression. Similar to adherence to cessation treatment, nicotine dependence and waterpipe use were also associated with severity of nicotine withdrawal symptoms. It's important that in countries like Syria where waterpipe use is prevalent to include a special component in cessation programs that takes into account the use of waterpipe concurrently with cigarettes to ensure that smokers who intend to quit will not substitute with waterpipe use.

Furthermore, this research shows that abstinence from smoking was associated with weight gain among smokers who attempt to quit in a low-income country setting. 
Additionally, smoking to control weight, having unsuccessful quitting attempts in the past due to weight gain, and being female were associated with post-cessation weight gain. This information has the potential to improve cessation rates by identifying smokers who are at higher risk of weight gain after quitting. For this group of smokers, incorporating interventions such as dietary regimens and physical activity into cessation programs is recommended.

Collectively, our findings increase the understanding of factors that are associated with adherence to cessation treatment, nicotine withdrawal symptoms and post-cessation weight gain among smokers who attempt to quit in a low-income country setting. This information will provide valuable guide for clinicians and researchers in designing future tailored and effective cessation interventions in Syria and other countries with similar developmental level and cultural background. 


\section{VITA}

\section{ZIYAD BEN TALEB}

2000-2007

2008-2009

2010-2012

2011-2012

2012-2013

2014-present

2013-present
MD Medicine

University of Tripoli

Tripoli, Libya

DOMH Occupational Medicine and health

University of Pretoria

Pretoria, South Africa

M.P.H, Environmental and Occupational Health

Florida International University

Miami, Florida

Research Assistant

Florida International University

Miami, Florida

Teaching Assistant

Florida International University

Miami, Florida

Graduate Assistant

Florida International University

Miami, Florida

Doctoral Candidate

Florida International University

Miami, Florida

\section{PUBLICATIONS (Selected)}

Ben Taleb, Z., Ward, K.D, Asfar, T., Jaber, R., Auf, R., Maziak, W. (2016). Predictors of nicotine withdrawal symptoms: findings from the first randomized smoking cessation trial in a lowincome country setting. International Journal of Public Health.1-8. [Epub ahead of print] 
Ben Taleb, Z., Ward, K.D, Asfar, T., Jaber, R., Bahelah, R., Maziak, W. (2016). Smoking cessation and changes in body mass index: findings from the first randomized cessation trial in low-income country setting. [Under review]

Jaber, R., Ben Taleb, Z., Bahelah, R., Madhivanan, P., Maziak, W. (2016). Perception, Intention, and Attempts to Quit Smoking among Jordanian Adolescents: Findings from Irbid longitudinal Study, 2008-2011. International Journal of Tuberculosis. [In press]

Gollub, E. L., \& Ben Taleb, Z. (2016). Gender in children's firearm deaths: using the data to guide interventions. American Journal of Medicine. [In press]

Ben Taleb, Z, Ward, K. D., Asfar, T., Bahelah, R., \& Maziak, W. (2015). Predictors of adherence to pharmacological and behavioral treatment in a cessation trial among smokers in Aleppo, Syria. Drug and Alcohol Dependence, 153, 167-172.

Maziak, W., Ben Taleb, Z., Bahelah, R., Islam, F., Jaber, R., Auf, R., \& Salloum, R. G. (2015).The global epidemiology of waterpipe smoking.Tobacco control, 24(Suppl 1), i3-i12.

Ben Taleb, Z., Bahelah, R., Fouad, F. M., Coutts, A., Wilcox, M., \& Maziak, W. (2015). Syria: health in a country undergoing tragic transition. International Journal of Public Health, 60(1), 6372.

Ben Taleb, Z., \& Maziak, W. (2014). Harm reduction and e-cigarettes: not evidence-based. The Lancet Oncology, 15(3), e104.

Ben Taleb, Z, \& Bahelah, R. (2014). Viewpoint: methanol poisoning outbreak in Libya: a need for policy reforms. Journal of Public Health Policy, 35(4), 489-498.

Ben Taleb, Z. (2014). Delayed tobacco plain packaging: how much more evidence do we need?. Journal of Adolescent Health, 3(54), 364.

Ben Taleb, Z. (2014). Snus usage: Harm induction or harm reduction?. Scandinavian Journal of Public Health, 42(3), 225-226.

Gollub, E. L., \& Ben Taleb, Z. (2014). Re:"In Memoriam: Mervyn Susser, MB, BCh, DPH”. American Journal of Epidemiology, kwu335. 